\title{
Systematic analysis of nuclear gene function in respiratory growth and expression of the mitochondrial genome in S. cerevisiae
}

\author{
Maria Stenger ${ }^{1}$, Duc Tung Le ${ }^{1}$, Till Klecker ${ }^{1, *}$ and Benedikt Westermann ${ }^{1, *}$ \\ ${ }^{1}$ Zellbiologie, Universität Bayreuth, 95440 Bayreuth, Germany. \\ * Corresponding Authors: \\ Benedikt Westermann, Zellbiologie, NW1, Universität Bayreuth, 95440 Bayreuth; Phone: +49-921-554300; Fax: +49-921-554301; \\ E-mail: benedikt.westermann@uni-bayreuth.de \\ Till Klecker, Zellbiologie, Universität Bayreuth, 95440 Bayreuth, Germany; E-mail: till.klecker@uni-bayreuth.de
}

\begin{abstract}
The production of metabolic energy in form of ATP by oxidative phosphorylation depends on the coordinated action of hundreds of nuclearencoded mitochondrial proteins and a handful of proteins encoded by the mitochondrial genome (mtDNA). We used the yeast Saccharomyces cerevisiae as a model system to systematically identify the genes contributing to this process. Integration of genome-wide high-throughput growth assays with previously published large data sets allowed us to define with high confidence a set of $\mathbf{2 5 4}$ nuclear genes that are indispensable for respiratory growth. Next, we induced loss of mtDNA in the yeast deletion collection by growth on ethidium bromide-containing medium and identified twelve genes that are essential for viability in the absence of mtDNA (i.e. petite-negative). Replenishment of mtDNA by cytoduction showed that respiratory-deficient phenotypes are highly variable in many yeast mutants. Using a mitochondrial genome carrying a selectable marker, $A R G 8^{m}$, we screened for mutants that are specifically defective in maintenance of $\mathrm{mtDNA}$ and mitochondrial protein synthesis. We found that up to $\mathbf{1 7 6}$ nuclear genes are required for expression of $\mathrm{mi}-$ tochondria-encoded proteins during fermentative growth. Taken together, our data provide a comprehensive picture of the molecular processes that are required for respiratory metabolism in a simple eukaryotic cell.
\end{abstract}

doi: $10.15698 /$ mic2020.09.729

Received originally: 07.02.2020;

In revised form: 19.06.2020,

Accepted 23.06.2020,

Published 30.06.2020.

Keywords: mitochondria, mitochondrial DNA, oxidative phosphorylation, petite mutant, yeast.
Abbreviations:
5'FOA - 5-fluoroorotic acid; EtBr-ethidium bromide; MIOREX - mitochondrial organization of gene expression; mIDNA - mitochondrial DNA; SGA - synthetic genetic array; vATPase-vacuolar ATPase.

\section{INTRODUCTION}

Most eukaryotic cells rely on mitochondrial respiration to liberate energy from metabolites and convert it to the universal energy currency, ATP. This process, also called oxidative phosphorylation, is performed by the respiratory chain Large multisubunit protein complexes in the mitochondrial inner membrane transfer electrons from reduced substrates provided by the citric acid cycle to molecular oxygen. At the same time, they pump protons from the matrix across the inner membrane into the intermembrane space. This proton gradient fuels the ATP synthase that operates like a molecular turbine and uses the proton motive force for the synthesis of ATP [1, 2]. The respiratory chain complexes are mosaics of subunits encoded by nuclear and mitochondrial genes. Defects result in devastating diseases [3] and the accumulation of mutations in the mitochondrial genome is thought to constitute an important factor contributing to aging [4-6].

The mitochondrial proteome consists of about 900 (in yeast) to 1,500 (in humans) different proteins $[7,8]$. While most of the mitochondrial proteins are encoded by nuclear genes and imported in a post-translational manner [9], only a handful of proteins are encoded by the mitochondrial DNA (mtDNA). The gene content of mitochondrial genomes varies between organisms. In general, mtDNAs encode the two mitochondrial rRNAs, a partial or full complement of tRNAs, some subunits of the respiratory chain complexes, and, at least in some organisms, some protein subunits of the mitochondrial ribosome [10]. In humans, the mtDNA encodes 13 respiratory chain subunits, including seven subunits of the NADH dehydrogenase (complex I), one subunit of the cytochrome $b c_{1}$ complex (complex III), three subunits of the cytochrome $c$ oxidase (complex IV), 
and two subunits of the ATP synthase (complex V) [4]. In budding yeast Saccharomyces cerevisiae the mtDNA encodes seven respiratory chain subunits and one ribosomal subunit [11]: the $C O B$ gene encodes cytochrome $b$ (complex III), COX1, COX2, and COX3 encode subunits of complex IV, ATP6, ATP8, and ATP9 encode subunits of complex $V$, and VAR1 encodes a protein of the small subunit of the mitochondrial ribosome. It is estimated that only about $15 \%$ of the mitochondrial proteins are directly involved in energy metabolism, while $20-25 \%$ of the mitochondrial proteome is required to maintain mtDNA and orchestrate mitochondrial gene expression [7].

S. cerevisiae is a powerful model organism to study the role of mitochondria in energy metabolism because it can satisfy its energy requirements by either fermentation or respiration, depending on the available carbon source. Oxidative phosphorylation and mtDNA are dispensable as long as yeast cells are grown on fermentable carbon sources, such as glucose, fructose, or galactose. Even in the presence of oxygen, glycolytic fermentation with ethanol and $\mathrm{CO}_{2}$ as end products is the preferred metabolic pathway for the generation of ATP. Most respiratory functions are repressed under these conditions (catabolite repression). Only when fermentable carbon sources become limiting, genes required for oxidative phosphorylation are induced and ATP is produced by metabolizing nonfermentable carbon sources, such as ethanol, glycerol, or lactate $[12,13]$. Respiratory-deficient yeast mutants are termed petite (French: small) or pet because they form small colonies on non-fermentable media with limiting amounts of fermentable carbon sources $[14,15]$. Cytoplasmic petite mutants contain mutations or lesions in the mitochondrial genome [rho-] or completely lack mtDNA $\left[\mathrm{rho}^{\circ}\right]$ whereas nuclear petite mutants contain mutations of genes located in the nuclear genome. Nuclear pet genes encode enzymes of the citric acid cycle, subunits and assembly factors of the respiratory chain, proteins involved in maintenance and inheritance of mtDNA, factors required for mitochondrial transcription and translation, and proteins involved in mitochondrial dynamics and other functions [16-18]. In contrast to most other eukaryotes, including many yeasts, $S$. cerevisiae does not have a respiratory chain complex I [19, 20]. Its function has been replaced by an alternative, single amino acid chain NADH dehydrogenase, Ndi1, which transfers electrons from NADH to ubiquinone but does not pump protons [21, 22].

Several large-scale studies contributed to the identification of nuclear pet genes in yeast [18, 23-26]. However, these studies yielded largely different results, and a consensus of the complement of genes required for respiratory growth and maintenance of the mitochondrial genome in yeast is still lacking. We developed an integrative experimental approach for genome-wide mutant analysis, generating a high confidence set of nuclear pet genes and a comprehensive list of genes required for maintenance of mtDNA. We are confident that our data will be a valuable resource to estimate the contribution of particular genes and cellular pathways to respiratory growth and expression of mitochondria-encoded proteins in budding yeast.

\section{RESULTS AND DISCUSSION}

\section{Definition of a high confidence set of nuclear pet genes}

The yeast deletion collection contains mutants of all ca. 4,800 non-essential yeast genes (corresponding to about $83 \%$ of all yeast genes) and constitutes a great resource for the systematic and genome-wide analysis of gene function [27-29]. Three previous studies have made use of it to identify pet genes by plating the strains on media containing non-fermentable carbon sources: Dimmer et al. identified 341 pet mutants in the homozygous diploid collection [23], Luban et al. identified 355 pet mutants in the MATa collection [25], and Merz and Westermann identified 319 pet mutants in the MAT $\alpha$ collection [18]. Even though the numbers of pet genes identified in each individual screen were very similar, the overlap was surprisingly small: only 176 pet mutants were found in all of the three screens [18].

Which factors may account for largely diverging results in three very similar screens? The complement of genes covered by different versions of the yeast deletion collection may vary. For example, deletion mutants of 140 newly identified small ORFs became available only in 2006 [30], i.e. after two of the three screens were performed. Also, there are several errors associated with the strains of the deletion collections [28]. Phenotypes caused by secondsite mutations that segregate away from the marker allele were estimated to occur in about $6.5 \%$ of haploid deletion mutants [31]. Up to $8 \%$ of the deletion strains are thought to have retained a wild type copy of the targeted gene presumably because of aneuploidy or a duplication event [31-33]. Deletions of ORFs may result in compensatory second-site mutations, often affecting nutrient responses and/or heat stress-induced cell death [34]. Deletions may also affect the function of neighboring genes [35]. Last but not least, good yeast husbandry is required to minimize errors associated with the deletion collection [28]. It has been estimated that over one third of the data obtained from a primary screen of the collection may consist of false positives or false negatives [32].

To define a high confidence set of nuclear pet genes in S. cerevisiae, we first scored the growth of the MATa deletion collection on plates with non-fermentable carbon sources. Using a high precision pinning robot, cells were first plated in a high density array on glucose-containing YPD plates, grown to colonies, and then transferred to glycerol-containing YPG plates. We observed that 278 deletion mutants failed to grow on YPG. When we compared this new list of pet genes to the previous three screens we found 113 mutants that were respiratory-deficient in all four screens (Figure 1A).

We then calculated a pet score for all yeast genes. We defined the pet score as the number of times a gene was identified as a pet gene divided by the number of times this deletion mutant was screened; i.e. the maximum pet score of 1 means that a deletion mutant was always found to be respiratory-deficient, whereas a pet score of 0.25 means that a mutant was found to be respiratory-deficient in only one out of four screens. These results are compiled in Table S1. This table contains the systematic gene name, the 
A

Luban et al., 2005
355 genes

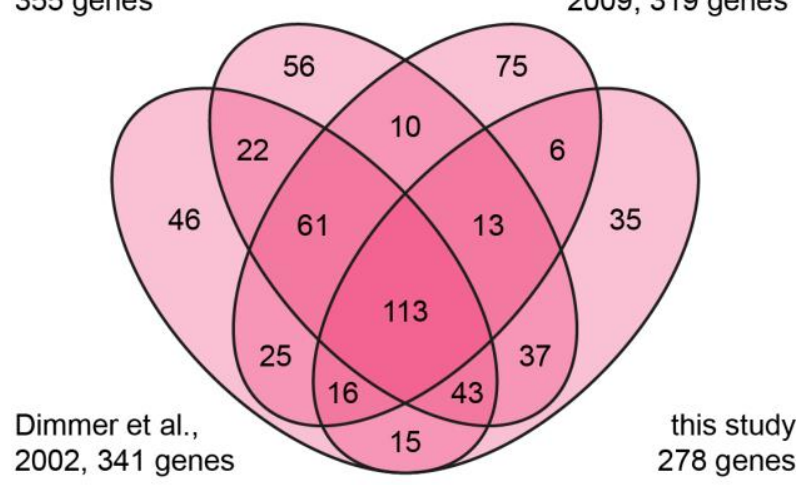

B

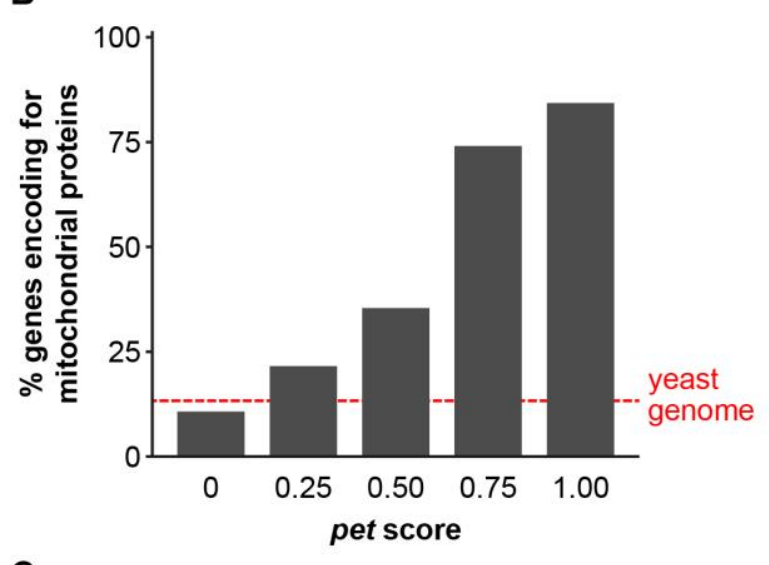

C

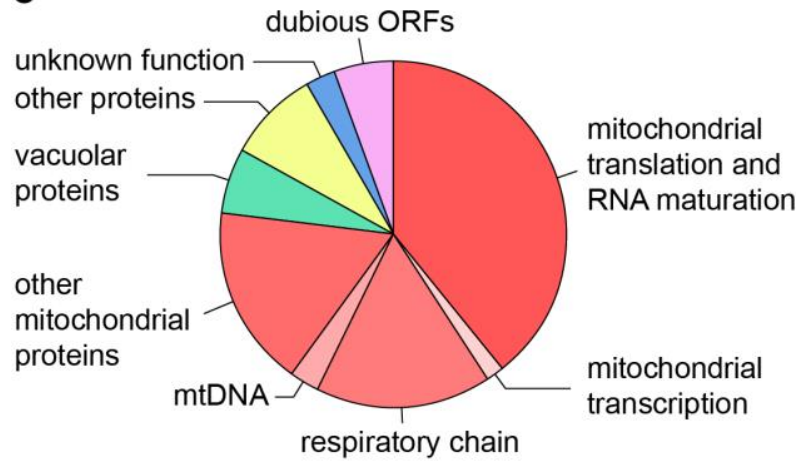

FIGURE 1: Defining a set of high confidence nuclear pet mutants. (A) Venn diagram comparing the results of four different screens $([18,23,25]$ and this study) for mutants with a pet phenotype. In each case, genome-wide collections of viable deletion mutants were analyzed and a pet phenotype was attributed to strains that were unable to grow on rich media containing glycerol as nonfermentable carbon source. (B) A pet score was derived from the four screens depicted in A by comparing the times a pet phenotype was reported for each gene to the times the deletion mutant was analyzed. See text for details. Viable deletion mutants were grouped according to their pet score and analyzed for the percentage of encoded proteins that were found in a high confidence mitochondrial proteome [8]. A detailed list containing the results from $A$ and $B$ can be found in Table S1. (C) Mutants with a pet score higher than 0.5, referred to as high confidence pet mutants, were manually grouped into functional categories. Lists of the genes present in each group can be found in Tables 1 and S2. standard gene name, a brief description of the protein function according to the Saccharomyces Genome Database, SGD [36], the presence of the protein in a high confidence mitochondrial proteome [8], the results of the four pet screens $([18,23,25]$ and this work), and the pet score.

Next, we correlated the pet score with a known localization of the gene product in mitochondria. We found that about $84 \%$ of the genes with a pet score of 1 and about $74 \%$ of the genes with a pet score of 0.75 encode mitochondrial proteins. This fraction was reduced to about $35 \%$ for a pet score of 0.5 and about $22 \%$ for a pet score of 0.25 (Figure 1B). Thus, a high pet score clearly correlates with a mitochondrial function of the gene product. We propose that genes with a pet score higher than 0.5 should be regarded as high confidence pet genes. This definition requires that a high confidence pet mutant has to repeatedly show a respiratory-deficient phenotype, but it does not exclude mutants that yielded one false-negative result. According to this definition there are 254 high confidence pet genes in yeast, $79 \%$ of which encode mitochondrial proteins (Tables 1 and S2).

High confidence pet genes encode proteins involved in mitochondrial translation and RNA maturation (39.4\%), respiratory chain components and assembly factors (16.5\%), mitochondrial transcription (1.6\%), mtDNA metabolism (2.8\%), other mitochondrial proteins (16.9\%), vacuolar proteins $(5.9 \%)$, other known proteins $(8.7 \%)$, proteins of unknown function (2.8\%), and dubious ORFs (5.5\%) (Figure 1C, Tables 1 and S2). All dubious ORFs overlap with genes with known functions in mitochondria ( $\mathrm{Ta}$ ble S2).

A large number of mutants lacking subunits or assembly factors of the vacuolar ATPase (vATPase) were found to have a high pet score, including $\Delta v m a 1, \Delta v m a 3, \Delta v m a 4$, $\Delta v m a 5, \Delta v m a 6, \Delta v m a 8, \Delta v m a 9, \Delta v m a 10, \Delta v m a 11, \Delta v m a 16$, $\Delta v m a 21$, and $\Delta v m a 22$. This is in accordance with previously published observations (see e.g. [18, 37-39]). Addition of iron or copper to the medium restores respiratory growth of vATPase mutants $[38,39]$, indicating that they retained respiratory competence. In line with this, we found that several mutants lacking proteins involved in metal ion homeostasis show a high pet score (Table S1). These include the high affinity plasma membrane iron or copper transporters Ftr1 and Ctr1 and the iron or copper homeostasis transcription factors Aft1 and Mac1. Intriguingly, mitochondrial iron content and biogenesis of iron sulfur cluster proteins are reduced by loss of vATPase activity, and supply of exogenous iron rescues this defect [40-42]. Furthermore, defects in vacuole function result in elevated cytosolic cysteine, which in turn impairs mitochondrial respiration by limiting iron availability [42]. Taken together, it appears that the pet phenotype of vATPase mutants is caused by compromised metal ion homeostasis in the cytosol.

It should be noted that pet phenotypes may vary between different strain backgrounds. Our analysis is based on genome-wide screens with the yeast deletion collection that was generated using strains BY4741, BY4742, BY4743, and to a lesser extent BY4730 and BY4739 [29]. Strains of 
TABLE 1. High confidence pet genes in yeast. Genes were manually grouped into the functional categories shown in Figure 1C. More details can be found in Tables S1 and S2.

\begin{tabular}{|c|c|c|c|c|c|}
\hline Standard name & ORF & Standard name & ORF & Standard name & ORF \\
\hline \multicolumn{6}{|c|}{ Mitochondrial translation and RNA maturation } \\
\hline$A E P 1$ & YMR064W & MRPL15 & YLR312W-A & MSK1 & YNL073W \\
\hline$A E P 2$ & YMR282C & MRPL16 & YBLO38W & MSM1 & YGR171C \\
\hline AEP3 & YPLO05W & MRPL17 & YNL252C & MSR1 & YHR091C \\
\hline AlM10 & YER087W & MRPL19 & YNL185C & MSS51 & YLR203C \\
\hline ATP22 & YDR350C & MRPL20 & YKR085C & MST1 & YKL194C \\
\hline ATP25 & YMRO98C & MRPL22 & YNL177C & MSW1 & YDR268W \\
\hline$C B P 1$ & YJL209W & MRPL23 & YOR150W & MSY1 & YPLO97W \\
\hline CBP2 & YHLO38C & MRPL24 & YMR193W & MTG1 & YMR097C \\
\hline CBS1 & YDL069C & MRPL25 & YGR076C & MTG2 & YHR168W \\
\hline CBS2 & YDR197W & MRPL27 & YBR282W & NAM2 & YLR382C \\
\hline CCM1 & YGR150C & MRPL31 & $Y K L 138 C$ & PET111 & YMR257C \\
\hline DIA4 & YHR011W & MRPL32 & YCR003W & PET112 & YBLO80C \\
\hline GEP3 & YOR205C & MRPL33 & YMR286W & PET122 & YER153C \\
\hline GEP5 & YLR091W & MRPL36 & YBR122C & PET123 & YOR158W \\
\hline HER2 & YMR293C & MRPL37 & YBR268W & РET309 & YLR067C \\
\hline IFM1 & YOLO23W & MRPL38 & YKL170W & PET494 & YNR045W \\
\hline IMG1 & YCR046C & MRPL4 & YLR439W & PET54 & YGR222W \\
\hline IMG2 & YCR071C & MRPL4O & YPL173W & RMD9 & YGL107C \\
\hline MEF1 & YLR069C & MRPL49 & YJL096W & $R M L 2$ & YELO5OC \\
\hline MEF2 & YJL102W & MRPL51 & YPR100W & $R R F 1$ & YHR038W \\
\hline MHR1 & YDR296W & MRPL6 & YHR147C & $R R G 8$ & YPR116W \\
\hline MNE1 & YOR350C & MRPL7 & YDR237W & RSM18 & YER050C \\
\hline$M R F 1$ & YGL143C & MRPL8 & YJL063C & RSM19 & YNR037C \\
\hline$M R P 1$ & YDR347W & MRPL9 & YGR220C & RSM22 & $Y K L 155 C$ \\
\hline MRP10 & YDL045W-A & MRPS12 & YNR036C & RSM23 & YGL129C \\
\hline MRP17 & YKLO03C & MRPS16 & YPL013C & RSM24 & YDR175C \\
\hline MRP20 & YDR405W & MRPS28 & YDR337W & RSM27 & YGR215W \\
\hline MRP21 & YBLO9OW & MRPS5 & YBR251W & $R S M 7$ & YJR113C \\
\hline MRP4 & YHL004W & MRPS8 & YMR158W & SLM5 & YCR024C \\
\hline MRP51 & YPL118W & MRS1 & YIR021W & SLS1 & YLR139C \\
\hline MRP7 & YNLO05C & $M R \times 14$ & YDR115W & SWS2 & YNL081C \\
\hline MRPL10 & YNL284C & MSD1 & YPL104W & TUF1 & YOR187W \\
\hline MRPL11 & YDL202W & MSE1 & YOLO33W & & \\
\hline MRPL13 & YKR006C & MSF1 & YPR047W & & \\
\hline \multicolumn{6}{|c|}{ Mitochondrial transcription } \\
\hline MSS116 & YDR194C & MTF2 & YDLO44C & & \\
\hline MTF1 & YMR228W & RPO41 & YFLO36W & & \\
\hline \multicolumn{6}{|c|}{ Respiratory chain components and assembly factors } \\
\hline ATP1 & YBLO99W & COR1 & YBLO45C & $I M P 1$ & YMR150C \\
\hline ATP10 & YLR393W & $\operatorname{cox} 10$ & YPL172C & IMP2 & YMR035W \\
\hline ATP11 & YNL315C & $\operatorname{cox} 11$ & YPL132W & MSS2 & YDL107W \\
\hline ATP12 & YJL180C & $\operatorname{cox} 12$ & YLR038C & PET100 & YDR079W \\
\hline ATP15 & YPL271W & $\operatorname{cox} 18$ & YGR062C & PET117 & YER058W \\
\hline ATP17 & YDR377W & $\operatorname{cox} 19$ & YLL018C-A & QCR2 & YPR191W \\
\hline ATP2 & YJR121W & $\operatorname{cox} 20$ & YDR231C & QCR7 & YDR529C \\
\hline ATP3 & YBR039W & $\operatorname{COX5A}$ & YNL052W & QCR8 & YJL166W \\
\hline ATP4 & YPL078C & cox6 & YHR051W & $R I P 1$ & YELO24W \\
\hline ATP5 & YDR298C & $\operatorname{cox} 7$ & $Y M R 256 C$ & SCO1 & YBR037C \\
\hline ATP7 & YKL016C & $\operatorname{cox} 9$ & YDL067C & $S D H 1$ & $Y K L 148 C$ \\
\hline$B C S 1$ & YDR375C & CYC3 & YALO39C & $S D H 2$ & YLLO41C \\
\hline CBP3 & YPL215W & CYT1 & YOR065W & SDH5 & YOLO71W \\
\hline CBP4 & YGR174C & CYT2 & YKL087C & SHY1 & YGR112W \\
\hline
\end{tabular}


TABLE 1 (continued). High confidence pet genes in yeast. Genes were manually grouped into the functional categories shown in Figure 1C. More details can be found in Tables S1 and S2.

\begin{tabular}{|c|c|c|c|c|c|}
\hline Standard name & ORF & Standard name & ORF & Standard name & ORF \\
\hline \multicolumn{6}{|l|}{ mtDNA } \\
\hline$A B F 2$ & YMR072W & MIP1 & YOR330C & $R I M 1$ & YCR028C-A \\
\hline$H M I 1$ & YOL095C & MSH1 & YHR120W & & \\
\hline MGM101 & YJR144W & PIF1 & YML061C & & \\
\hline \multicolumn{6}{|c|}{ Other mitochondrial proteins } \\
\hline$A C O 1$ & $Y L R 304 C$ & FTR1 & YER145C & MDJ1 & YFL016C \\
\hline AFG3 & YER017C & FUM1 & YPL262W & MET7 & YOR241W \\
\hline AIM22 & YJL046W & FZO1 & YBR179C & $M G M 1$ & YOR211C \\
\hline CAT5 & YOR125C & GCV3 & YAL044C & NFU1 & YKLO4OC \\
\hline CEM1 & YER061C & GGC1 & YDL198C & OAR1 & $Y K L 055 C$ \\
\hline COQ1 & YBR003W & GRX5 & YPL059W & OCT1 & $Y K L 134 C$ \\
\hline COQ10 & YOL008W & HEM14 & YER014W & OXA1 & YER154W \\
\hline COQ2 & YNR041C & HTD2 & YHR067W & PPA2 & $Y M R 267 W$ \\
\hline COQ3 & YOLO96C & IBA57 & YJR122W & PPT2 & YPL148C \\
\hline COQ4 & YDR204W & $\mid S A 1$ & YLL027W & SOM1 & YELO59C-A \\
\hline COQ5 & YML110C & ISA2 & YPR067W & SSQ1 & YLR369W \\
\hline COQ6 & YGR255C & $K G D 2$ & YDR148C & SUV3 & YPLO29W \\
\hline COQ9 & $Y L R 201 C$ & LIP2 & YLR239C & YTA12 & YMRO89C \\
\hline DSS1 & YMR287C & $\angle P D 1$ & YFL018C & & \\
\hline ETR1 & YBR026C & MCT1 & YOR221C & & \\
\hline \multicolumn{6}{|l|}{ Vacuolar proteins } \\
\hline DID4 & $Y K L 002 W$ & VMA21 & YGR105W & VMA6 & YLR447C \\
\hline VMA1 & YDL185W & VMA22 & YHR060W & VMA8 & YEL051W \\
\hline VMA10 & YHR039C-A & VMA3 & YELO27W & VMA9 & YCL005W-A \\
\hline VMA11 & YPL234C & VMA4 & YOR332W & VPS16 & YPL045W \\
\hline VMA16 & YHR026W & VMA5 & $Y K L 080 W$ & VPS33 & $Y L R 396 C$ \\
\hline \multicolumn{6}{|l|}{ Other proteins } \\
\hline AFT1 & YGL071W & HAP2 & YGL237C & $R P L 1 B$ & YGL135W \\
\hline BUD25 & YER014C-A & HAP3 & YBL021C & SNF1 & YDR477W \\
\hline CTR1 & YPR124W & HAP4 & YKL109W & SNF4 & YGL115W \\
\hline CYS3 & YAL012W & HAP5 & YOR358W & SWI3 & YJL176C \\
\hline$D E F 1$ & YKLO54C & $\angle C B 5$ & YLR260W & TPD3 & YAL016W \\
\hline DOC1 & YGL240W & $M A C 1$ & YMR021C & VPS34 & YLR240W \\
\hline$F B P 1$ & $Y L R 377 C$ & $R N R 4$ & YGR180C & & \\
\hline GRR1 & YJRO9OC & RPB9 & YGLO70C & & \\
\hline \multicolumn{6}{|c|}{ Proteins of unknown function } \\
\hline $\operatorname{IRC19}$ & YLL033W & RRG9 & $Y N L 213 C$ & YNL184C & YNL184C \\
\hline$R R G 1$ & YDR065W & SOV1 & YMR066W & & \\
\hline$R R G 7$ & YOR305W & YDR114C & YDR114C & & \\
\hline \multicolumn{6}{|l|}{ Dubious ORFs } \\
\hline YBL100C & YBL100C & YGR219W & YGR219W & YNL170W & YNL170W \\
\hline YCLOO7C & YCLOO7C & YJL120W & YJL120W & YOR200W & YOR200W \\
\hline YDL068W & YDL068W & YJR114W & YJR114W & YOR331C & YOR331C \\
\hline YDR230W & YDR230W & $Y K L 169 C$ & $Y K L 169 C$ & YPRO99C & YPRO99C \\
\hline YGL218W & YGL218W & YLR202C & YLR202C & & \\
\hline
\end{tabular}

the BY series [43] are derivatives of the widely used laboratory strain S288C [44], which also was used as a source for sequencing of the yeast genome [45]. Quantitative trait locus (QTL) mapping revealed alleles of four genes that affect respiratory growth of BY strains in comparison to other laboratory strains and wild type isolates [46]: MKT1$30 D$, encoding a putative translation regulator that translo- cates to $P$ bodies upon ethanol stress [47]; sal1-1, encoding an ATP/ADP carrier in the mitochondrial inner membrane [48]; CAT5-911, encoding a mitochondrial protein required for ubiquinone (coenzyme Q) biosynthesis [49]; and MIP1$661 A$, encoding the mitochondrial DNA polymerase [50]. Furthermore, S288C-derived strains carry a defective Ty 1 transposon inserted in the $3^{\prime}$ region of the HAP1 ORF. This 
insertion severely compromises the function of the Hap1 transcription factor which is involved in the regulation of gene expression in response to levels of heme and oxygen, including respiratory chain components [51]. Taken together, these alleles make the strains that were used to construct the deletion collection particularly vulnerable to perturbations of mitochondrial functions.

\section{pet phenotypes are highly variable for many gene dele- tions}

Petite phenotypes may be highly variable even within the same genetic background. Strikingly, deletions of the dubious ORFs $\Delta y g / 218 w$ and $\Delta y n / 170 w$ have high pet scores (0.75), whereas deletions of their overlapping proteincoding genes $\Delta m d m 34$ and $\Delta p s d 1$, respectively, have pet scores of 0 (see Table S2). A detailed study on Mdm34 (alternative name $\mathrm{Mmm} 2$ ) reported that $\Delta m d m 34$ cells were initially deficient in growth on plates containing nonfermentable carbon sources, but single colonies were clearly visible after 10-14 days and could immediately grow after transfer to fresh medium [52]. Another study showed that $\Delta m d m 34$ mutants rapidly accumulate suppressor mutations in the VPS13 gene [53]. Similarly, the $\triangle p s d 1$ mutant was found to have a strong growth defect on YPG but only a moderate growth defect on YPEG plates [54]. Furthermore, a previous study showed that the $\Delta y g / 218 \mathrm{w}$ mutant had lost its mtDNA in the original yeast deletion library but was able to stably maintain it after cytoduction, and $\Delta y n / 170 w$ belonged to a group of 77 mutants that grew on non-fermentable carbon sources only after cells had the chance to adapt to the medium [18]. Thus, $\Delta m d m 34$, $\Delta y g / 218 w, \Delta p s d 1$, and $\Delta y n / 170 w$ - and certainly many other deletion strains - show highly variable growth behaviors on non-fermentable carbon sources.

Mitochondrial genome instability is responsible for the occurrence of spontaneous petite mutants in populations of yeast cells. While true wild type and domesticated S. cerevisiae strains give rise to relatively few [ $\left.\mathrm{rho}^{-}\right]$or $\left[\mathrm{rho}^{\circ}\right]$ colonies, many laboratory strains produce high frequencies of spontaneous petites [55]. The sal1-1, CAT5-91I, and MIP1-661A alleles present in the strains of the BY series are responsible for an about 100 -fold elevated rate of loss of mtDNA [46]. We reasoned that a significant number of mutants may have shown a pet phenotype in screens of the yeast deletion collection because of spontaneous loss of mtDNA. To test this, we first induced loss of mtDNA by plating the MATa deletion collection on ethidium bromide (EtBr) containing medium [56] to avoid heteroplasmy. We then freshly introduced wild type mtDNA by cytoduction [57] and assayed again growth on non-fermentable carbon sources (Fig. 2A).

The MATa deletion collection was passaged three times on glucose-containing YPD medium supplemented with $\mathrm{EtBr}$ to induce loss of mtDNA. Successful elimination of the mitochondrial genome was verified by lack of growth of all strains on glycerol-containing YPG medium and absence of mtDNA nucleoids in 24 randomly chosen mutants upon DAPI staining and fluorescence microscopy. Twelve strains failed to grow on EtBr-containing medium (Table 2). This
A

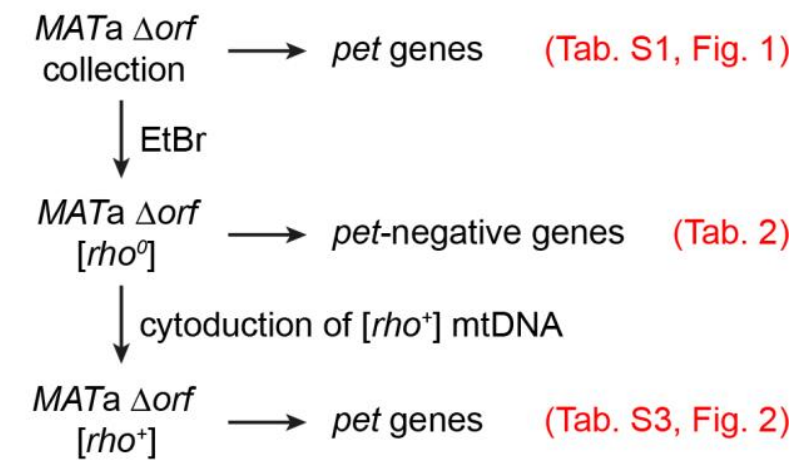

B

before cytoduction 278 pet genes

after cytoduction 268 pet genes

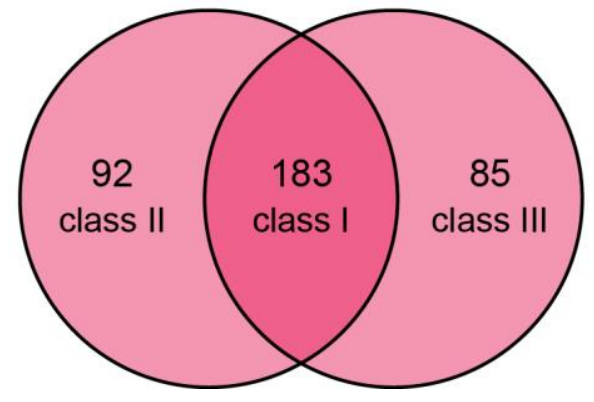

FIGURE 2: Contribution of mtDNA maintenance to the variability of pet phenotypes. (A) Flow chart depicting the experimental outline. In brief, the whole deletion collection was treated with $\mathrm{EtBr}$ to induce loss of mtDNA. Functional [rho $\left.{ }^{+}\right]$mtDNA was reintroduced into each strain by cytoduction. The resulting $\left[\mathrm{rho}^{+}\right]$ deletion collection was tested for growth on rich media containing glycerol as nonfermentable carbon source. See text for details. (B) Venn diagram comparing the sets of deletion mutants that showed a pet phenotype before and after EtBr-treatment and cytoduction. The mutants were grouped into three classes: Mutants that exhibited a pet phenotype before and after cytoduction were classified as class I mutants, those that were rescued by cytoduction were grouped into class II, and mutants that were unable to grow on media with glycerol as the carbon source only after cytoduction are referred to as class III mutants. Three of the 278 pet mutants from the original deletion collection exhibited a petite-negative phenotype and were omitted from the analysis.

group of mutants is expected to include petite-negative mutants, i.e. mutants that cannot live without their mtDNA, even when they are grown on fermentable carbon sources. In the absence of a functional respiratory chain the $\mathrm{F}_{1}$-ATP synthase and the major ADP/ATP carrier, Pet9, are required to maintain a membrane potential, $\Delta \Psi$, across the inner membrane. Under these conditions, the $F_{1}$-ATP synthase hydrolyzes ATP, generating excess ADP in the matrix. $A D P^{3-}$ is then exchanged for ATP4- imported from the cytosol by ADP/ATP carriers in the inner membrane. The import of one net negative charge per pair of transported adenine nucleotides builds up a membrane 
TABLE 2. Mutants that were unable to grow on EtBr-containing medium. Descriptions of gene functions were taken from the Saccharomyces Genome Database [36] with some manual annotations.

\begin{tabular}{lll}
\hline Standard name & ORF & Gene function \\
\hline APD1 & $Y B R 151 w$ & Protein of unknown function \\
\hline ATP1 & $Y B L 099 w$ & Alpha subunit of the $\mathrm{F}_{1}$ sector of mitochondrial $\mathrm{F}_{1} \mathrm{~F}_{\mathrm{o}}$ ATP synthase \\
\hline ATP11 & $Y N L 315 c$ & $\begin{array}{l}\text { Molecular chaperone required for the assembly of alpha and beta subunits into the } \mathrm{F}_{1} \\
\text { sector of mitochondrial } \mathrm{F}_{1} \mathrm{~F}_{\mathrm{o}} \text { ATP synthase }\end{array}$ \\
\hline ATP12 & $Y J L 180 c$ & Assembly factor for $\mathrm{F}_{1}$ sector of mitochondrial $\mathrm{F}_{1} \mathrm{~F}_{\mathrm{o}}$ ATP synthase \\
\hline CLC1 & $Y G R 167 w$ & Clathrin light chain \\
\hline NAT3 & $Y P R 131 c$ & Catalytic subunit of the NatB N-terminal acetyltransferase \\
\hline OCH1 & $Y G L 038 c$ & Mannosyltransferase of the cis-Golgi apparatus \\
\hline ROX3 & $Y B L 093 c$ & Subunit of the RNA polymerase II mediator complex \\
\hline RPB9 & $Y G L 070 c$ & RNA polymerase II subunit B12.6 \\
\hline SSD1 & $Y D R 293 c$ & Translational repressor \\
\hline SWI6 & $Y L R 182 w$ & Transcription cofactor \\
\hline TIM18 & $Y O R 297 c$ & Component of the mitochondrial TIM22 complex, involved in insertion of polytopic pro- \\
& & teins into the inner membrane \\
\hline
\end{tabular}

potential, which is required to maintain protein import into the matrix, an activity which is essential for cell viability [58, 59]. This explains why mutants $\Delta a t p 1$, lacking the alpha subunit of the $F_{1}$-ATP synthase, and $\Delta a t p 11$ and $\Delta a t p 12$, lacking $F_{1}$-ATP synthase assembly factors, were unable to grow on EtBr-containing medium. $\Delta$ tim 18 , lacking a subunit of the TIM22 protein import complex in the inner membrane, was already identified in a previous screen for petite-negative mutants [59]. We have not verified a role of the other genes in conferring a petite-negative phenotype.

Previous work by Dunn et al. [59] reported the identification of twelve petite-negative mutants in a screen of 3,791 haploid yeast deletion strains. It should be noted that the overlap between this screen an ours is surprisingly small ( $\Delta$ tim 18 is the only mutant that was identified both by Dunn et al. and in the present study). While the role of the $F_{1}$ ATP synthase in conferring a petite negative phenotype is well established [58], the $\Delta a t p 2$ mutant was not detected in our screen, and $\Delta a t p 1, \Delta a t p 11$, and $\Delta a t p 12$ were not found by Dunn et al. We consider it likely that the petite-negative phenotype is highly variable, like the pet phenotype, and its appearance might depend on strain background and experimental conditions.

In a next step we mated the MATa $\left[r h o^{\circ}\right]$ deletion collection with the cytoduction donor strain J1362, which is karyogamy-defective due to the kar1 $\Delta 15$ allele and carries a Kluyveromyces lactis URA3 gene on each chromosome to allow counterselection on medium containing 5'FOA (5fluoroorotic acid) [60]. After cytoduction and growth on 5 'FOA we observed that the wild type mtDNA donated by $J 1362$ restored the ability to grow on medium with nonfermentable carbon source, YPG, for most strains. $268 \mathrm{mu}$ tants failed to grow on YPG (Table S3). A comparison of this set of pet mutants with the set of 275 pet mutants that were originally present in this collection (i.e. 278 pet mutants minus three petite-negative pet mutants; listed in Tables $\mathbf{2}$ and S1) revealed an overlap of 183 pet genes (Fig.
2B). Of these, 161 mutants, corresponding to $88 \%$, are high confidence pet mutants.

92 mutants that were respiratory-deficient in the original collection were cured by cytoduction. Of these, only $29.3 \%$ are high confidence pet genes suggesting that they acquire a respiratory-deficient phenotype only under some circumstances. As the nuclear genome was not altered during the cytoduction experiment, we assume that second-site mutations, aneuploidy, or gene duplications in most cases are not responsible for the variations of growth behavior before and after cytoduction. It is reasonable to assume that at least some of the 92 mutants that were cured by cytoduction had lost their mtDNA after creation of the yeast deletion collection. For 41 mutants, some residual growth could be observed upon transfer to fresh YPG medium, indicating that functional mtDNA was present. To test whether the remaining 51 strains had lost their mitochondrial genome, we mated them with the $\Delta$ mip1 mutant, which is $\left[r h o^{\circ}\right]$. We observed that 48 heterozygous diploid strains failed to grow on YPG, indicating that the parental strains indeed lacked functional mtDNA (Table S4). Thus, spontaneous loss of mtDNA contributes to the variations of pet phenotypes that are observed in a substantial number of yeast deletion mutants.

Unexpectedly, 85 mutants were respiratory-competent before growth on EtBr-containing medium and failed to be rescued by cytoduction. This group contains only nine high confidence pet mutants, corresponding to $10.6 \%$, suggesting that most of these genes are dispensable for respiration. To test whether these are random effects, we repeated the cytoduction experiment and obtained 232 mutants that were respiratory-deficient after cytoduction. 213 of these mutants were already found in the first cytoduction experiment, indicating that the results are highly reproducible (Table S3). Of these, 46 respiratory-competent strains reproducibly became respiratory-deficient only after cytoduction. This relatively large number suggests that this 
effect is not random. However, it is unknown whether cytoduction is inefficient in these mutants, e.g. because of mating defects, or whether they acquired respiratory deficiency for other reasons. For example, it is possible that $\mathrm{EtBr}$ treatment induced second site mutations, as EtBr was shown to increase the mutation frequency of the nuclear genome [61].

Taken together, our results suggest that pet phenotypes of many gene deletions are highly variable, at least in BY laboratory yeast strains. It has been suggested that environmental factors, nutrient supply, and epigenetic mechanisms may contribute to the plasticity of pet phenotypes [18]. Thus, loss of mtDNA is only one of several reasons for an acquired pet phenotype. Alternative reasons may include an insufficient relief of catabolite repression, or the accumulation of irreversible damage independent of the presence of mtDNA.

Genes required for expression and maintenance of the mitochondrial genome

It is estimated that as many as 250 proteins might be required for the expression of only eight proteins that are encoded by the mitochondrial genome in yeast $[62,63]$. To identify the genes that are specifically involved in this process, we devised a screen that allowed us to select for mitochondrial gene expression independent of respiratory functions and the carbon source of the medium (Fig. 3A). Arg8 is a nuclear-encoded mitochondrial enzyme that catalyzes the fourth step in the biosynthesis of the arginine precursor ornithine $[64,65]$. The $A R G 8^{m}$ allele is a synthetic gene adapted to the mitochondrial genetic code and integrated into mtDNA. It fully complements a nuclear $\Delta a r g 8$ deletion at the level of cell growth and therefore can serve as an auxotrophic marker synthesized in mitochondria [66].

To screen for mutants defective in $A R G 8^{m}$ expression, we first introduced the genomic $\triangle \arg 8$ allele into the MATa yeast deletion collection by synthetic genetic array (SGA) technology $[67,68]$ and obtained 4,523 mutants that were unable to grow in the absence of arginine (i.e. they are arginine-auxotroph). Then, we passaged the strains on EtBr-containing medium to induce loss of mtDNA, introduced a $\left[A R G 8^{m}{ }^{r h O^{+}}\right]$mitochondrial genome [69] by cytoduction and scored for restoration of growth on glucosecontaining minimal medium without arginine (i.e. arginine prototrophy). We obtained 198 mutants that were unable to grow on minimal medium lacking arginine (Table S5).
A

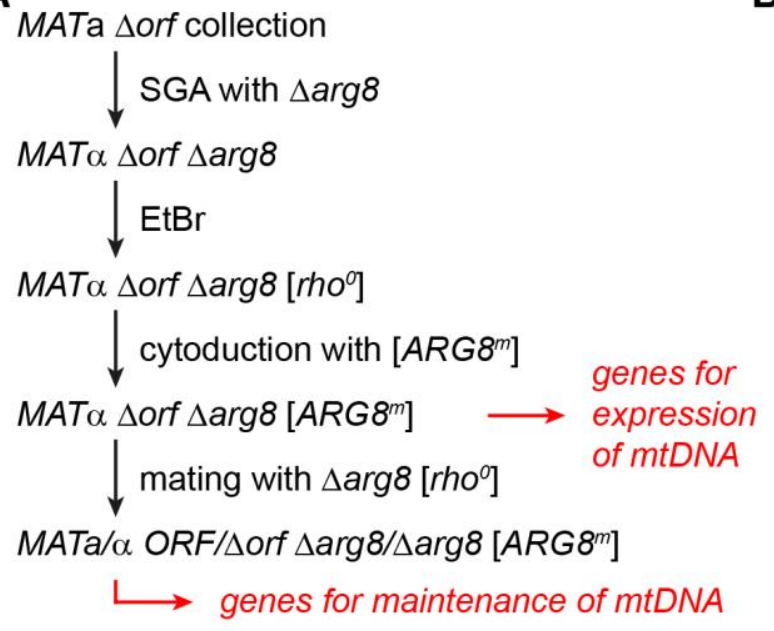

B

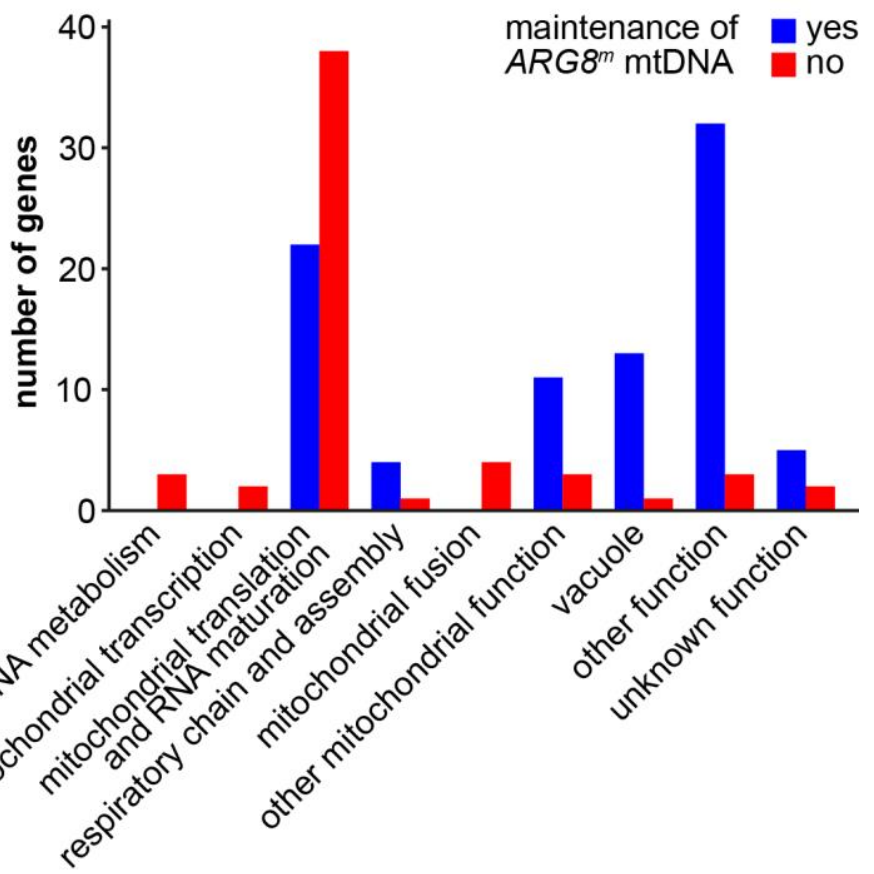

FIGURE 3: Defining the genes required for expression and maintenance of the mitochondrial genome. (A) Flow chart depicting the outline of the experiment. A $\Delta$ orf $\Delta a r g 8$ double mutant collection was generated using SGA technology (see methods). The mitochondrial genome was eliminated from all double mutants by treatment with EtBr. A functional mtDNA containing the ARG8m allele was introduced into all strains by cytoduction. Mutants that were unable to grow on media lacking arginine after cytoduction were considered to have lost their mtDNA or to be unable to express the $A R G 8^{m}$ gene. To test for this, the resulting $\triangle$ orf $\triangle \arg 8\left[A R G 8^{m}\right]$ double mutant collection was crossed with a $\Delta \arg 8\left[\mathrm{rho}^{\circ}\right]$ strain and the resulting diploid strains were scored for growth on media lacking arginine. Mutants that were unable to grow were considered to suffer from mtDNA instability. See text for details. (B) The mutants that had lost their mtDNA or that were unable to express the $A R G 8^{m}$ gene were manually grouped into functional categories. Depicted is how often each functional group is represented among these two sets of mutants. Blue bars represent mutants that maintained the $\left[A R G 8^{m}\right]$ mitochondrial genome, but were unable to express $\operatorname{Arg}^{\mathrm{m}}$ (i.e. the genes listed in Table 3; these are the "genes for expression of mtDNA" minus "genes for maintenance of mtDNA" in panel A). Red bars represent mutants that lost the $\left[A R G 8^{m}\right]$ mitochondrial genome (i.e. the genes listed in Table 4; these are the "genes for maintenance of mtDNA" in panel A that could be confirmed by DAPI staining). 
This group of mutants is expected to pertain all nuclear genes that are essential for maintenance of mtDNA and expression of mitochondria-encoded proteins. Several deletion mutants were respiratory-competent, as judged by their pet score, but unable to grow on medium lacking arginine after cytoduction. This latter group includes mutants defective in certain steps of amino acid biosynthesis, including $\Delta \arg 1, \Delta \arg 3, \Delta \arg 4, \Delta \arg 5,6, \Delta c p a 1$, and $\Delta c p a 2$. It is conceivable that these strains are arginine-auxotroph because steps of amino acids metabolism other than Arg8dependent synthesis of ornithine are affected. Furthermore, several mutants lack proteins known to be required during mating, including $\Delta a g a 2, \Delta e r g 6, \Delta h t / 1, \Delta s s t 2, \Delta s t e 3$, and $\Delta$ ste20. We assume that these mutants remained arginine-auxotroph because they failed to receive the [ARG $\left.{ }^{m}\right]$ mitochondrial genome by cytoduction. We excluded both groups and all dubious ORFs from further analysis, yielding a total number of 176 mutants that could not support mitochondrial protein synthesis. $97(55 \%)$ of these mutants were high confidence pet mutants and $61 \%$ of the encoded proteins have a known mitochondrial localization.

The analysis of arginine auxotrophy of $\Delta \arg 8\left[A R G 8^{m}\right]$ yeast deletion strains allowed the identification of a set of genes required for expression of mitochondria-encoded proteins. However, it does not reveal whether the defect is at the level of maintenance of mtDNA or mitochondrial protein synthesis. To discriminate between these possibilities, we tested whether arginine prototrophy of the yeast deletion strains can be restored by mating with a $\Delta a r g 8$ $\left[r^{\circ} o^{\circ}\right]$ strain. We reasoned that growth on minimal media lacking arginine should be restored in the resulting heterozygous strain when the yeast deletion mutant contributes the $A R G 8^{m}$ gene on its mtDNA and the mating partner contributes the missing ORF required for $\operatorname{Arg}^{\mathrm{m}}$ expression. If, however, the yeast deletion strain is unable to maintain mtDNA the heterozygous strain will remain arginineauxotroph because it lacks the $A R G 8^{m}$ allele.

We observed that mating restored arginine prototrophy in 87 deletion mutants, indicating that these mutants are able to maintain mtDNA (Table S5). This group is expected to include mutants lacking proteins involved in mitochondrial transcription, translation and other processes required for mitochondrial protein synthesis. Consequently, we found many deletion mutants lacking mitochondrial ribosomal subunits or tRNA synthetases (Table 3). Arginine prototrophy could not be restored by mating of 68 deletion mutants, suggesting loss of the $\left[A R G 8^{m}\right]$ mtDNA. For 21 deletion mutants the results were intermediate, suggesting that mtDNA stability is reduced in these mutants. Combining the two latter sets of mutants, we identified $89 \mathrm{mu}$ tants that displayed an instable mtDNA phenotype (Table S5; see methods for details).

To better define the set of genes required for maintenance of mtDNA we re-analyzed these 89 mutants. We repeated the genetic analysis and again tested their growth on media lacking arginine after cytoduction with the $\left[A R G 8^{m} r{ }^{+}\right]$mitochondrial genome. 16 strains that did not show arginine auxotrophy were excluded from further analysis. The remaining mutants were again subjected to mating with the $\Delta \arg 8\left[\mathrm{rho}^{\circ}\right]$ strain, and cells were then stained with DAPI. 16 mutants showed nucleoids in fluorescence microscopy indicating that mtDNA can be maintained; i.e. they are either $\left[\mathrm{rho}^{+}\right]$or $\left[\mathrm{rho}^{-}\right] .57$ mutants were arginine-auxotroph and devoid of mtDNA nucleoids; i.e. $\left[\mathrm{rho}^{\circ}\right]$ (Table S6). We conclude that these strains are severely defective in maintenance of mtDNA (Table 4). This group is expected to include mutants lacking proteins involved in replication and inheritance of mtDNA. Indeed, we found mutants lacking proteins involved in mtDNA metabolism, such as $\Delta m g m 101, \Delta m i p 1$, and $\Delta r i m 1$. It is known that mitochondrial fusion is essential for maintenance of mtDNA [70]. In agreement with this, fusion-defective mutants $\Delta f z o 1, \Delta m g m 1, \Delta p c p 1$, and $\Delta u g o 1$ were also found to be $\left[r h o^{\circ}\right]$.

Four previous studies [18, 71-73] have reported alternative approaches that systematically identified genes required for maintenance of mtDNA. First, a screen of 4,985 mutants of the MAT $\alpha$ deletion collection revealed $118 \mathrm{mu}$ tants that remained petite after mating with $\triangle$ mip1 and cytoduction with wild type mtDNA [18]. Second, DAPI staining of 466 MATa yeast deletions with a previously reported pet phenotype [24] revealed 102 mutants lacking detectable mtDNA [71]. Third, colony hybridization of 5,148 yeast deletion strains with probes specific for mtDNA and nuclear DNA revealed 180 mutants lacking mtDNA [72]. And fourth, genome sequencing of nearly all of the strains of the homozygous diploid yeast deletion collection identified 165 mutants lacking mtDNA [73]. A comparison of these screens with our results is shown in Table S7. We consider it likely that different experimental conditions and the use of different versions of the yeast deletion library account for most of the variations of the results. Furthermore, mutants that were found only once (or maybe twice) might lose their mtDNA only after prolonged growth on fermentable carbon sources and therefore are not essential for maintenance of mtDNA. These strains were largely excluded by our approach since we freshly introduced mtDNA by cytoduction and then selected for its maintenance by an auxotrophic marker.

Recent research has revealed many molecular details of mtDNA replication in yeast. It is thought to depend on the coupling of recombination, rolling circle replication, and template switching [74]. Strikingly, already 35 years ago it was found that mitochondrial protein synthesis is required for maintenance of mtDNA [75]. A dependency of mtDNA maintenance on mitochondrial translation has also been reported for the fission yeast Schizosaccharomyces pombe [76]. Consistently, we found that 38 deletion mutants lacking genes required for mitochondrial protein synthesis failed to maintain a functional $\left[A R G 8^{m}\right]$ genome - this is by far the largest group of genes required for this process. This is in good agreement with previous studies, which also reported that mitochondrial protein synthesis is particularly important for mtDNA maintenance $[18,71]$. Our results suggest that mitochondrial translation is required for mitochondrial genome maintenance even when respiratory activity is not required. 
TABLE 3. Genes required for expression of $\mathrm{Arg}^{\mathrm{m}}$ in mitochondria. The yeast deletion collection was treated as outlined in Fig. $3 A$. This table is an excerpt of Table S5. Genes with known functions in arginine biosynthesis or mating and dubious ORFs were excluded from this list. Genes required for maintenance of $\left[A R G 8^{m}\right]$ mtDNA are listed in Table 4.

\begin{tabular}{|c|c|c|c|c|c|}
\hline Standard name & ORF & Standard name & ORF & Standard name & ORF \\
\hline \multicolumn{6}{|c|}{ Mitochondrial translation and RNA maturation } \\
\hline AIM10 & YERO87W & MRPL13 & YKR006C & MSF1 & YPR047W \\
\hline GEP3 & YOR205C & MRPL22 & YNL177C & MTG1 & YMR097C \\
\hline HER2 & YMR293C & MRPL32 & YCROO3W & PET111 & YMR257C \\
\hline IFM1 & YOLO23W & MRPL38 & YKL170W & PET112 & YBLO80C \\
\hline IMG2 & YCR071C & MRPL6 & YHR147C & QRI5 & YLR204W \\
\hline MHR1 & YDR296W & MRPL9 & YGR220C & RSM7 & YJR113C \\
\hline MRF1 & YGL143C & MRPS5 & YBR251W & & \\
\hline MRM1 & YOR201C & MSE1 & YOLO33W & & \\
\hline \multicolumn{6}{|c|}{ Respiratory chain components and assembly factors } \\
\hline ATP15 & YPL271W & ATP7 & YKLO16C & & \\
\hline ATP17 & YDR377W & $\mathrm{SDH} 4$ & YDR178W & & \\
\hline \multicolumn{6}{|c|}{ Other mitochondrial function } \\
\hline ACO2 & YJL200C & MIS1 & YBR084W & POS5 & YPL188W \\
\hline GGC1 & YDL198C & MTM1 & YGR257C & sUV3 & YPL029W \\
\hline GRX5 & YPLO59W & OXA1 & YER154W & TOM6 & YOR045W \\
\hline MDL2 & YPL270W & PIM1 & YBLO22C & & \\
\hline \multicolumn{6}{|c|}{ Vacuole-related function } \\
\hline$B R O 1$ & YPLO84W & VMA16 & YHR026W & VPS24 & $Y K L 041 W$ \\
\hline DID4 & YKL002W & VMA21 & YGR105W & VPS61 & YDR136C \\
\hline DOA4 & YDR069C & VMA3 & YELO27W & VPS63 & YLR261C \\
\hline SNF8 & YPLO02C & VMA5 & YKLO80W & & \\
\hline VAM3 & YOR106W & VMA9 & YCL005W-A & & \\
\hline \multicolumn{6}{|l|}{ Other function } \\
\hline BIT2 & YBR270C & KCS1 & YDR017C & RHO4 & YKR055W \\
\hline COY1 & YKL179C & KEX1 & YGL203C & RPE1 & YJL121C \\
\hline CTL1 & YMR180C & $\angle C B 4$ & YOR171C & RTS1 & YOR014W \\
\hline CTR9 & YOL145C & LEM3 & YNL323W & RTT103 & YDR289C \\
\hline CUS2 & YNL286W & MAF1 & YDR005C & SFM1 & YOR021C \\
\hline$D A K 2$ & YFL053W & $N G L 2$ & YMR285C & SFP1 & YLR403W \\
\hline EGT2 & YNL327W & $N P R 2$ & YELO62W & $S L Y 41$ & YOR307C \\
\hline GAL10 & YBR019C & OPI3 & YJR073C & SNF1 & YDR477W \\
\hline INO2 & YDR123C & PEX5 & YDR244W & TFB5 & YDR079C-A \\
\hline INO4 & YOL108C & PEX8 & YGR077C & YPS7 & YDR349C \\
\hline IRA2 & YOLO81W & PIB2 & YGLO23C & & \\
\hline \multicolumn{6}{|c|}{ Unknown function } \\
\hline FYV6 & YNL133C & $R R G 9$ & YNL213C & YPL205C & YPL205C \\
\hline$R R G 1$ & YDR065W & YDR114C & YDR114C & & \\
\hline
\end{tabular}

What might be the functional link between mitochondrial protein synthesis and mtDNA maintenance? The ATP synthase consists of nuclear and mitochondria-encoded subunits. The mitochondrial genes ATP6, ATP8, and ATP9 encode subunits that form the proton-conducting $F_{0}$ part. It has been shown that incomplete assembly of the ATP synthase can lead to uncoupling of the mitochondrial membrane potential, $\Delta \Psi$, by passive proton transport through the $F_{0}$ part. Complete breakdown of $\Delta \Psi$ is lethal to the cell because it impedes the import of vital proteins into the matrix. Lethality of ATPase assembly mutants can be suppressed by loss of mtDNA concomitant with loss of the proton-conducting channel [69]. It has been suggested that alterations of mitochondrial translation may frequently lead to aberrant expression of ATP synthase subunits, formation of an incorrectly assembled proton channel, and breakdown of $\Delta \Psi$. In this scenario, mutants retain some residual mitochondrial translation activity, and loss of mtDNA prevents synthesis of the proton channel-forming $F_{0}$ ATP synthase subunits and thereby promotes cell survival. Thus, loss of mtDNA in mutants defective in mitochondrial translation might be a rescuing event [77].

Alternatively, mitochondrial translation might play a more active role in maintenance of mtDNA. Recently, it 
TABLE 4. Genes required for maintenance of $\left[A R G 8^{m}\right]$ mtDNA. The yeast deletion collection was treated as outlined in Fig. $3 A$, and mutants showing an instable mtDNA phenotype were confirmed by DAPI staining. This table is an excerpt of Table S6. Genes with known functions in arginine biosynthesis or mating and dubious ORFs were excluded from this list.

\begin{tabular}{|c|c|c|c|c|c|}
\hline Standard name & ORF & Standard name & ORF & Standard name & ORF \\
\hline \multicolumn{6}{|c|}{ mtDNA metabolism } \\
\hline MGM101 & YJR144W & MIP1 & YOR330C & RIM1 & YCR028C-A \\
\hline \multicolumn{6}{|c|}{ Mitochondrial transcription } \\
\hline MTF1 & YMR228W & $R P 041$ & YFLO36W & & \\
\hline \multicolumn{6}{|c|}{ Mitochondrial translation and RNA maturation } \\
\hline$A E P 3$ & YPLO05W & MRPL17 & YNL252C & MSW1 & YDR268W \\
\hline ATP22 & YDR350C & MRPL20 & YKR085C & MSY1 & YPLO97W \\
\hline DIA4 & YHR011W & MRPL23 & YOR150W & PET123 & YOR158W \\
\hline IMG1 & YCR046C & MRPL27 & YBR282W & PET130 & YJL023C \\
\hline MRP17 & YKL003C & MRPL35 & YDR322W & $R M L 2$ & YELO5OC \\
\hline MRP20 & YDR405W & MRPL37 & YBR268W & $R R G 8$ & YPR116W \\
\hline MRP21 & YBLO9OW & MRPL49 & YJL096W & RSM18 & YER050C \\
\hline MRP4 & YHL004W & MRPL51 & YPR100W & RSM19 & YNR037C \\
\hline MRP51 & YPL118W & MRPS12 & YNR036C & RSM23 & YGL129C \\
\hline$M R P 7$ & YNLOO5C & MRPS16 & YPL013C & RSM24 & YDR175C \\
\hline MRPL10 & YNL284C & MRPS35 & YGR165W & $R S M 27$ & YGR215W \\
\hline MRPL11 & YDL202W & MSK1 & YNL073W & sWS2 & YNL081C \\
\hline MRPL16 & YBLO38W & MST1 & $Y K L 194 C$ & & \\
\hline \multicolumn{6}{|c|}{ Respiratory chain components and assembly factors } \\
\hline COX5A & YNLO52W & & & & \\
\hline \multicolumn{6}{|c|}{ Mitochondrial fusion } \\
\hline FZO1 & YBR179C & $P C P 1$ & YGR101W & & \\
\hline MGM1 & YOR211C & UGO1 & YDR470C & & \\
\hline \multicolumn{6}{|c|}{ Other mitochondrial function } \\
\hline MDJ1 & YFLO16C & OCT1 & YKL134C & PPA2 & YMR267W \\
\hline \multicolumn{6}{|c|}{ Vacuole-related function } \\
\hline VPS33 & YLR396C & & & & \\
\hline \multicolumn{6}{|l|}{ Other function } \\
\hline HPR1 & YDR138W & $R P P 2 A$ & YOLO39W & UAF30 & YOR295W \\
\hline \multicolumn{6}{|c|}{ Unknown function } \\
\hline LCL1 & YPL056C & SOV1 & YMR066W & & \\
\hline
\end{tabular}

was discovered that mitochondrial ribosomes interact with many proteins involved in the expression of mtDNA. Together they form large assemblies that were termed 'mitochondrial organization of gene expression' (MIOREX) complexes. Intriguingly, several proteins involved in mtDNA metabolism could be co-precipitated with native mitochondrial ribosomes, and a subset of MIOREX complexes was found to be associated with mtDNA nucleoids by super resolution microscopy. These observations point to an intimate connection of mtDNA maintenance and mitochondrial protein synthesis [78]. It is clear that the presence of an intact mitochondrial protein synthesis machinery is important for maintenance of the mitochondrial genome. However, the elucidation of the exact molecular mechanisms that functionally connect mitochondrial translation with maintenance of mtDNA still remains a challenge for the future.

\section{MATERIALS AND METHODS}

Strains, growth, and manipulation of yeast cells

Yeast strains used in this study are listed in Table 5. Standard methods and media were used for growth and manipulation of yeast cells $[55,79]$. Replica plating of high density arrays (HDAs in 96, 384, or 1,536 colonies format) was performed using a ROTOR HDA robot (Singer Instruments, Somerset, UK). Tetrad dissection was performed with a Singer MSM Series 300 micromanipulator equipped with an Acer n30 pocket PC (Singer Instruments).

To induce loss of mtDNA, yeast strains were passaged three times on YPD plates supplemented with $50 \mu \mathrm{g} / \mathrm{ml}$ ethidium bromide (EtBr). In case of yeast deletion collections, this was done in HDAs in a 1,536 colonies format. Subsequent growth on YPD or YPG plates was assayed in a 384 colonies format. Absence of mtDNA was tested in randomly chosen strains by DAPI staining and fluorescence microscopy as described [80]. 
TABLE 5. Yeast strains used in this study.

\begin{tabular}{|c|c|c|}
\hline Strain & Genotype & References \\
\hline BY4741 & MATa his $3 \Delta 1$ leu2 $\Delta 0$ met $15 \Delta 0$ ura $3 \Delta 0\left[\mathrm{rho}^{+}\right]$ & [43] \\
\hline BY4741[rho $\left.{ }^{\circ}\right]$ & MATa his $3 \Delta 1$ leu2 $\Delta 0$ met $15 \Delta 0$ ura $3 \Delta 0\left[\mathrm{rho}^{\circ}\right]$ & This study \\
\hline BY4742 & MATa his $3 \Delta 1$ leu $2 \Delta 0$ lys $2 \Delta 0$ ura $3 \Delta O\left[\mathrm{rho}^{+}\right]$ & [43] \\
\hline$\Delta m i p 1$ & MATa his $3 \Delta 1$ leu $2 \Delta O$ lys $2 \Delta O$ ura3 $\Delta O\left[\mathrm{rho}^{\circ}\right]$ & {$[27,29]$} \\
\hline$J 1361$ & 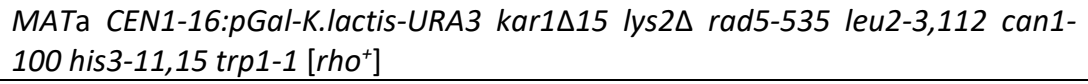 & {$[60]$} \\
\hline $\mathrm{J} 1361\left[\mathrm{rho}^{\circ}\right]$ & $\begin{array}{l}\text { MATa CEN1-16:pGal-K.lactis-URA3 kar1D15 lys2A rad5-535 leu2-3,112 can1- } \\
100 \text { his3-11,15 trp1-1 }\left[\text { rho }^{\circ}\right]\end{array}$ & This study \\
\hline $\mathrm{J} 1361\left[\mathrm{ARG8^{m }} \mathrm{rho}^{+}\right]$ & $\begin{array}{l}\text { MATa CEN1-16:pGal-K.lactis-URA3 kar1D15 lys2A rad5-535 leu2-3,112 can1- } \\
\left.100 \text { his3-11,15 trp1-1 [ARG8 } \text { rho }^{+}\right]\end{array}$ & This study \\
\hline$J 1362$ & $\begin{array}{l}\text { MAT } \alpha \text { CEN1-16:pGal-K.lactis-URA3 kar1D15 lys2D rad5-535 leu2-3,112 can1- } \\
100 \text { his3-11,15 trp1-1 }\left[\text { rho }^{+}\right]\end{array}$ & {$[60]$} \\
\hline $\mathrm{JC} 8\left[\mathrm{ARGB}^{m} \mathrm{rho}^{+}\right]$ & MATa kar1-1 leu1 $\left[\right.$ARGB $^{m}$ rho $\left.^{+}\right]$ & {$[50,69,87]$} \\
\hline Y8205 & 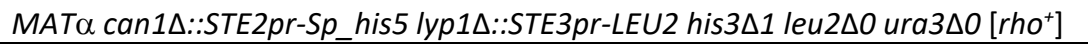 & [68] \\
\hline YDTL88 & MATa his $3 \Delta 1$ leu $2 \Delta 0$ met $15 \Delta 0$ ura3 $\Delta 0 \arg 8 \Delta:: H I S 3 M X 6\left[\mathrm{rho}^{\circ}\right]$ & This study \\
\hline YKO strains $^{1}$ & MATa his3 $\Delta 1$ leu2 $\Delta 0$ met15 $\Delta 0$ ura3 $\Delta 0$ orf $\Delta:: k a n M X 4\left[r_{h o}^{+}\right]$ & $\begin{array}{l}{[27,29] \text { and this }} \\
\text { study }\end{array}$ \\
\hline YKO strains $\left[\mathrm{rho}^{\circ}\right]$ & MATa his3 $\Delta 1$ leu $2 \Delta 0$ met $15 \Delta 0$ ura3 $\Delta 0$ orf $\Delta:: k a n M X 4\left[\mathrm{rho}^{\circ}\right]$ & This study \\
\hline YKO strains $\Delta a r g 8$ & 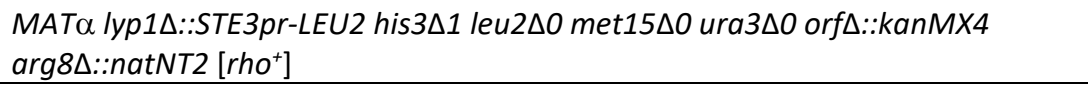 & This study \\
\hline $\begin{array}{l}\text { YKO strains } \Delta a r g 8 \\
{\left[r h o^{\circ}\right]}\end{array}$ & 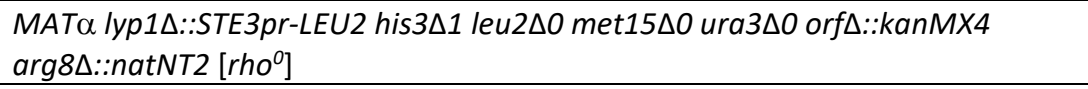 & This study \\
\hline $\begin{array}{l}\text { YKO strains } \Delta \text { arg8 } \\
{\left[A R G 8^{m} \text { rho }^{+}\right]}\end{array}$ & 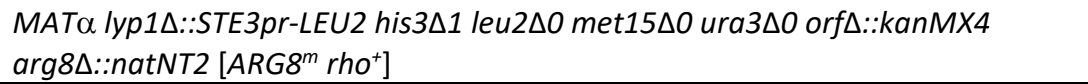 & This study \\
\hline $\begin{array}{lr}\text { heterozygous } & \text { YKO } \\
\text { strains } & \Delta a r g 8 \\
{\left[A R G 8^{m} \mathrm{rho}^{+}\right]} & \\
\end{array}$ & 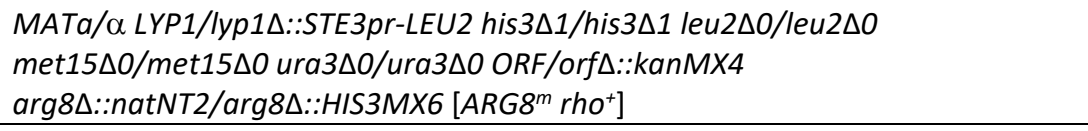 & This study \\
\hline YMS001 & 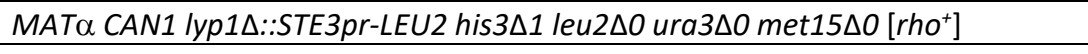 & This study \\
\hline YMSO02 & 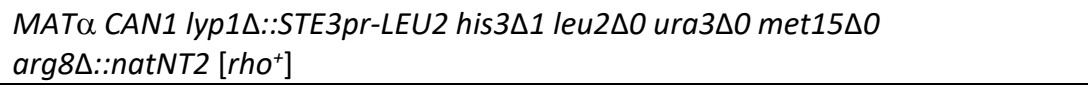 & This study \\
\hline YMSO03 & 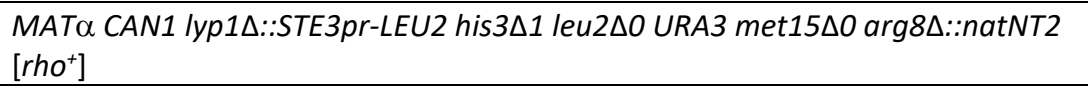 & This study \\
\hline YMSO04 & MAT $\alpha$ his3 $\Delta 1$ leu2 $\Delta 0$ lys $2 \Delta 0$ ura3 $\Delta 0$ [pRS415 LEU2] [rho $\left.{ }^{\circ}\right]$ & This study \\
\hline YMSO05 & 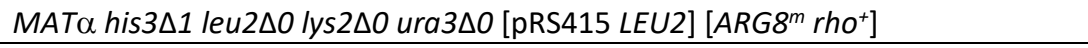 & This study \\
\hline
\end{tabular}

${ }^{1}$ Yeast knock-out strains from the yeast deletion collection

To delete the $A R G 8$ gene in a $\left[r^{\circ} o^{\circ}\right]$ strain we amplified the HIS3MX6 cassette from plasmid pFA6a-His3MX6 [81] using primers containing sequences homologous to regions flanking the ARG8 ORF, 5' ACA TTT TTT TCG TTT GTT AGA ATA ATT CAA GAA TCG CTA CCA ATC CGG ATC CCC GGG TTA ATT AA and 5' GAA AAA AAA AAA AAC AAT CTA TAC ATG ACA ATT TAC AAA GTA TAT GAA TTC GAG CTC GTT TAA AC, and transformed the PCR product into strain $\mathrm{BY} 4741\left[\mathrm{rho}^{\circ}\right]$ resulting in strain YDTL88.

\section{Cytoduction}

For cytoduction with donor strains J1631, J1632, and derivatives thereof, the mtDNA donor strain was grown to a lawn on a YPD plate, transferred as a 1,536 colonies HDA to a YPD plate, and incubated for 2 days at $30^{\circ} \mathrm{C}$. In parallel, the recipient strain collection was first grown on YPD plates in 384 colonies HDAs, up-arrayed to 1,536 colonies HDAs, and incubated for 2 days at $30^{\circ} \mathrm{C}$. Then, donor and recipient strains were combined, incubated for 1 day at $30^{\circ} \mathrm{C}$, passaged two times for 1-2 days on YPGal plates, passaged two times on SCGal plates supplemented with $50 \mathrm{mg} / \mathrm{l}$ uracil and $1 \mathrm{~g} / \mathrm{I} 5^{\prime} \mathrm{FOA}$ [82] and lacking lysine, and transferred to YPD, YPG, and/or SD plates lacking arginine.

\section{Construction of a $\Delta$ arg 8 yeast deletion collection}

The starting strain for SGA, Y8205, contains a $\Delta$ can1 deletion to allow the use of canavanine as a selection marker [68]. Canavanine, a structural analog of arginine, is taken up into the cell by an arginine permease encoded by the CAN1 gene and incorporated into proteins, leading to non-functional translation products [83]. As construction of a yeast deletion collection with a nuclear $\Delta \arg 8$ allele required the presence of functional Can1, we introduced a wild type CAN1 gene to facilitate arginine uptake and a URA3 gene as an alternative se- 
lectable marker into strain Y8205. The URA3 containing plasmid pRS416 [84] was first transformed into BY4741 [43]. This strain was mated with Y8205, diploids were selected on SD medium lacking methionine and uracil, and cells were subjected to sporulation and tetrad dissection. We selected haploid cells that were $M A T \alpha$, resistant to thialysine, sensitive to canavanine, and auxotroph for uracil and methionine, resulting in strain YMSO01. To delete the ARG8 gene in YMSO01, we amplified the natNT2 cassette conferring resistance to nourseothricin (NTC) from plasmid pYM-N7 [85] by PCR using primers containing sequences homologous to regions flanking the ARG8 ORF, 5' GTG ACT GCG AAC ATT TTT TTC GTT TGT TAG AAT AAT TCA AGA ATC GCT ACC AAT CGT ACG CTG CAG GTC GAC G and 5' ATA TAA AGA TGA AAA AAA AAA AAA CAA TCT ATA CAT GAC AAT TTA CAA AGT ATA TGA GCT CGA TTA CAA CAG GTG TTG TCC. Transformation of the PCR product into YMSO01 and selection of NTC-resistant clones resulted in strain YMS002. The wild type URA3 gene was amplified from strain D273-10B [86] using primers 5' TTG ATA AGA AGA GTA TTG AGA AGG GCA ACG and 5' TAT ATA TAC GCC AGT ACA CCT TAT CGG CCC. Transformation of the PCR product into YMSO02 and selection of uracil prototroph clones resulted in strain YMS003, which served as a starter strain for SGA.

The SGA to introduce the $\Delta a r g 8$ allele into the yeast deletion collection was performed essentially as described [68] with some modifications as outlined below. Strain YMSO03 was plated as a lawn on YPD plates and combined with HDAs (1,536 colonies format) of the MATa deletion collection on YPD plates. Diploids were selected by two passages on SD medium supplemented with G418 and lacking uracil. Sporulation was induced for 10 days at $22^{\circ} \mathrm{C}$. Selection of haploids was by subsequent selection rounds on SCD supplemented with $5^{\prime}$ FOA and thialysine and lacking leucine, SCD supplemented with 5'FOA, thialysine, and G418 and lacking leucine, and three passages on SCD supplemented with $5^{\prime} F O A$, thialysine, G418, and NTC and lacking leucine. To verify the replacement of $A R G 8$ by the $\Delta$ arg 8 allele, growth was tested on SD medium lacking arginine or uracil. 611 strains were still able to grow in the absence of arginine after the first SGA, and 590 strains after a second SGA. We combined the strains obtained in both SGAs resulting in a $\Delta a r g 8$ yeast deletion collection that allowed us to screen 4,523 deletion mutants. This corresponds to $90.9 \%$ of the 4,973 strains that were originally present in the collection. It should be noted that the $\Delta$ arg 8 deletion collection was MAT $\alpha$ because haploid selection was with the lyp1A::STE3pr-LEU2 allele.

\section{Construction of a $\left[\mathrm{ARG}^{\mathrm{m}} \mathrm{rho}^{+}\right]$cytoduction donor strain}

To introduce the $\left[A R G 8^{m} r \mathrm{O}^{+}\right]$mitochondrial genome [69] into the $\triangle a r g 8$ yeast deletion collection, a mtDNA donor was constructed as follows. Strain BY4742 was transformed with the LEU2 marker plasmid, pRS415 [84], and cured from mtDNA by growth on EtBr-containing medium, producing strain $\mathrm{YMSO04}$. Strain YMSOO4 was mated with JC8 $\left[\mathrm{ARG}^{\mathrm{m}} \mathrm{rho}^{+}\right]$and diploids were selected on SD minimal medium supplemented with histidine and lysine (KAR1 $\times$ kar1-1 crosses produce diploids with mixed parental genotypes at low frequency [87]). After sporulation and tetrad dissection strain YMSO05 was obtained. Strain J1361 [60] was cured from mtDNA by growth on EtBrcontaining medium and served as a recipient for mtDNA from strain YMS005. Cytoductants were selected on YPG medium supplemented with canavanine. The resulting strain, J1361
[ARG8 ${ }^{m}$ rho $^{+}$, was used as a mtDNA donor strain for cytoduction with the $\Delta \arg 8\left[r^{\circ} o^{\circ}\right]$ yeast deletion collection.

\section{Screen for maintenance of [ARG8 $\left.{ }^{m}\right]$ mtDNA}

The screen for maintenance of $\left[A R G 8^{m}\right]$ mtDNA was performed exclusively on media containing fermentable carbon sources. High density arrays in 384 or 1,536 colonies format were produced using a ROTOR HDA robot according to the scheme outlined in Fig. 3A. Growth of the individual strains was manually assessed. Biological replicates resulting from two $\Delta \arg 8$ SGAs (see above) were analyzed on the same plates with two technical replicates for each deletion mutant. Strains that were lost at any step of the replica plating or that retained arginine prototrophy after the $\Delta$ arg8 SGAs were omitted from further analysis. Only strains that were not rescued by cytoduction with the $\left[A R G 8^{m}\right]$ mtDNA were scored for growth after mating with the $\Delta \arg 8\left[r^{\circ} o^{\circ}\right]$ strain. These strains were classified into three categories: "rescue" indicates that growth on plates lacking arginine was restored, "no rescue" means that the strains remained arginine auxotroph after mating with the $\Delta \arg 8\left[r^{\circ} o^{\circ}\right]$ strain, and "ambiguous" refers to strains where the resulting phenotype was intermediate (see column "Screen result" in Table S5). The latter class also includes strains that showed opposite behavior between biological replicates, i.e. growth and no growth after mating with $\Delta \arg 8\left[r^{\circ} o^{\circ}\right]$. For each strain it is indicated in Table S5 whether both biological replicates were analyzed and whether they behaved identically. If at least one biological replicate showed arginine auxotrophy after mating with $\Delta \arg 8\left[\mathrm{rho}^{\circ}\right]$ the deletion mutant was considered to have an instable mtDNA phenotype.

\section{Venn diagrams}

Venn diagrams were generated using the online tool 'Venny' as described by Oliveros, J.C. (2007-2015) Venny. An interactive tool for comparing lists with Venn's diagrams. https://bioinfogp.cnb.csic.es/tools/venny/index.html

\section{ACKNOWLEDGEMENTS}

We thank Tom Fox, Nathalie Bonnefoy, and Alexander Kastaniotis for providing strains and the members of our lab for fruitful discussions and comments on the manuscript. This work was supported by Deutsche Forschungsgemeinschaft through grant WE 2714/6-1 and Elitenetzwerk Bayern through the Biological Physics program. The publication was funded by Deutsche Forschungsgemeinschaft and the University of Bayreuth in the funding programme Open Access Publishing.

\section{SUPPLEMENTAL MATERIAL}

All supplemental data for this article are available online at www.microbialcell.com.

\section{CONFLICT OF INTEREST}

The authors declare no conflicts of interest.

\section{COPYRIGHT}

(C) 2020 Stenger et al. This is an open-access article released under the terms of the Creative Commons Attribution (CC BY) license, which allows the unrestricted use, 
distribution, and reproduction in any medium, provided the original author and source are acknowledged.

\section{REFERENCES}

1. Saraste M (1999). Oxidative phosphorylation at the fin de siècle. Science 283(5407): 1488-1493. doi: 10.1126/science.283.5407.1488

2. Xu T, Pagadala V, Mueller DM (2015). Understanding structure, function, and mutations in the mitochondrial ATP synthase. Microbial Cell 2(4): 105-125. doi: 10.15698/mic2015.04.197

3. Smeitink J, van den Heuvel L, DiMauro S (2001). The genetics and pathology of oxidative phosphorylation. Nat Rev Genet 2(5): 342-352. doi: $10.1038 / 35072063$

4. Schon EA, DiMauro S, Hirano M (2012). Human mitochondrial DNA: roles of inherited and somatic mutations. Nat Rev Genet 13(12): 878890. doi: $10.1038 / \mathrm{nrg} 3275$

5. Trifunovic A, Wredenberg A, Falkenberg M, Spelbrink JN, Rovio AT, Bruder CE, Bohlooly YM, Gidlof S, Oldfors A, Wibom R, Tornell J, Jacobs HT, Larsson NG (2004). Premature ageing in mice expressing defective mitochondrial DNA polymerase. Nature 429(6990): 417-423. doi: $10.1038 /$ nature02517

6. Kauppila TES, Kauppila JHK, Larsson NG (2017). Mammalian mitochondria and aging: an update. Cell Metab 25(1): 57-71. doi: 10.1016/j.cmet.2016.09.017

7. Pfanner N, Warscheid B, Wiedemann N (2019). Mitochondrial proteins: from biogenesis to functional networks. Nat Rev Mol Cell Biol 20(5):267-284. doi: 10.1038/s41580-018-0092-0

8. Morgenstern $M$, Stiller SB, Lubbert $P$, Peikert CD, Dannenmaier $S$, Drepper F, Weill U, Hoss $P$, Feuerstein R, Gebert $M$, Bohnert $M$, van der Laan $M$, Schuldiner M, Schutze C, Oeljeklaus S, Pfanner N, Wiedemann N, Warscheid B (2017). Definition of a high-confidence mitochondrial proteome at quantitative scale. Cell Rep 19(13): 28362852. doi: 10.1016/j.celrep.2017.06.014

9. Neupert W, Herrmann JM (2007). Translocation of proteins into mitochondria. Annu Rev Biochem 76(1): 723-749. doi: 10.1146/annurev.biochem.76.052705.163409

10. Gray MW, Burger G, Lang BF (1999). Mitochondrial evolution. Science 283(5407): 1476-1481. doi: 10.1126/science.283.5407.1476

11. Foury F, Roganti T, Lecrenier N, Purnelle B (1998). The complete sequence of the mitochondrial genome of Saccharomyces cerevisiae. FEBS Lett 440(3): 325-331. doi: 10.1016/S0014-5793(98)01467-7

12. Piskur J, Rozpedowska E, Polakova S, Merico A, Compagno C (2006). How did Saccharomyces evolve to become a good brewer? Trends Genet 22(4): 183-186. doi: 10.1016/j.tig.2006.02.002

13. Kayikci Ö, Nielsen J (2015). Glucose repression in Saccharomyces cerevisiae. FEMS Yeast Res 15(6): 1-8. doi: 10.1093/femsyr/fov068

14. Ephrussi B, Hottinguer $H$, Tavlitzki J (1949). Action de l'acriflavine sur les levures II. Étude génétique du mutant "petite colonie". Ann Inst Pasteur 76: 419-442.

15. Williamson $D$ (2002). The curious history of yeast mitochondrial DNA. Nat Rev Genet 3(6): 475-481. doi: 10.1038/nrg814

16. Tzagoloff A, Dieckmann CL (1990). PET genes of Saccharomyces cerevisiae. Microbiol Rev 54(3): 211-225. doi: 10.1128/mmbr.54.3.211-225.1990

17. Contamine V, Picard M (2000). Maintenance and integrity of the mitochondrial genome: a plethora of nuclear genes in the budding
Please cite this article as: Maria Stenger, Duc Tung Le, Till Klecker and Benedikt Westermann (2020). Systematic analysis of nuclear gene function in respiratory growth and expression of the mitochondrial genome in S. cerevisiae. Microbial Cell 7(9): 234-249. doi: $10.15698 / \mathrm{mic} 2020.09 .729$ yeast. Microbiol Mol Biol Rev 64(2): 281-315. doi: 10.1128/MMBR.64.2.281-315.2000

18. Merz S, Westermann B (2009). Genome-wide deletion mutant analysis reveals genes required for respiratory growth, mitochondrial genome maintenance and mitochondrial protein synthesis in Saccharomyces cerevisiae. Genome Biol 10(9): R95. doi: 10.1186/gb-200910-9-r95

19. Büschges R, Bahrenberg G, Zimmermann M, Wolf K (1994). NADH: ubiquinone oxidoreductase in obligate aerobic yeasts. Yeast 10(4): 475-479. doi: 10.1002/yea.320100406

20. Goncalves AP, Videira A (2015). Mitochondrial type II NAD(P)H dehydrogenases in fungal cell death. Microbial Cell 2(3): 68-73. doi: 10.15698/mic2015.03.192

21. Marres CA, de Vries S, Grivell LA (1991). Isolation and inactivation of the nuclear gene encoding the rotenone-insensitive internal NADH: ubiquinone oxidoreductase of mitochondria from Saccharomyces cerevisiae. Eur J Biochem 195(3): 857-862. doi: 10.1111/j.1432 1033.1991.tb15775.x

22. Seo BB, Kitajima-Ihara T, Chan EK, Scheffler IE, Matsuno-Yagi A, Yagi T (1998). Molecular remedy of complex I defects: rotenoneinsensitive internal NADH-quinone oxidoreductase of Saccharomyces cerevisiae mitochondria restores the NADH oxidase activity of complex I-deficient mammalian cells. Proc Natl Acad Sci USA 95(16): 91679171. doi: 10.1073/pnas.95.16.9167

23. Dimmer KS, Fritz S, Fuchs F, Messerschmitt M, Weinbach N, Neupert W, Westermann B (2002). Genetic basis of mitochondrial function and morphology in Saccharomyces cerevisiae. Mol Biol Cell 13(3): 847-853. doi: 10.1091/mbc.01-12-0588

24. Steinmetz LM, Scharfe C, Deutschbauer AM, Mokranjac D, Herman ZS, Jones T, Chu AM, Giaever G, Prokisch H, Oefner PJ, Davis RW (2002). Systematic screen for human disease genes in yeast. Nat Genet 31(4): 400-404. doi: 10.1038/ng929

25. Luban C, Beutel M, Stahl U, Schmidt U (2005). Systematic screening of nuclear encoded proteins involved in the splicing metabolism of group II introns in yeast mitochondria. Gene 354: 72-79. doi: 10.1016/j.gene.2005.03.023

26. Hess DC, Myers CL, Huttenhower C, Hibbs MA, Hayes AP, Paw J, Clore JJ, Mendoza RM, Luis BS, Nislow C, Giaever G, Costanzo M, Troyanskaya OG, Caudy AA (2009). Computationally driven, quantitative experiments discover genes required for mitochondrial biogenesis. PLoS Genet 5(3): e1000407. doi: 10.1371/journal.pgen.1000407

27. Giaever G, Chu AM, Ni L, Connelly C, Riles L, Veronneau S, Dow S, Lucau-Danila A, Anderson K, Andre B, Arkin AP, Astromoff A, ElBakkoury M, Bangham R, Benito R, Brachat S, Campanaro S, Curtiss M, Davis K, Deutschbauer A, Entian KD, Flaherty P, Foury F, Garfinkel DJ, Gerstein M, Gotte D, Guldener U, Hegemann JH, Hempel S, Herman Z, et al. (2002). Functional profiling of the Saccharomyces cerevisiae genome. Nature 418(6896): 387-391. doi: 10.1038/nature00935

28. Giaever G, Nislow C (2014). The yeast deletion collection: a decade of functional genomics. Genetics 197(2): 451-465. doi: 10.1534/genetics.114.161620

29. Winzeler EA, Shoemaker DD, Astromoff A, Liang $H$, Anderson $K$, Andre B, Bangham R, Benito R, Boeke JD, Bussey H, Chu AM, Connelly 
C, Davis K, Dietrich F, Dow SW, El Bakkoury M, Foury F, Friend SH, Gentalen E, Giaever G, Hegemann JH, Jones T, Laub M, Liao H, Liebundguth $N$, Lockhart DJ, Lucau-Danila $A$, Lussier $M, M^{\prime}$ Rabet $N$, Menard P, et al. (1999). Functional characterization of the $S$. cerevisiae genome by gene deletion and parallel analysis. Science 285(5429): 901-906. doi: 10.1126/science.285.5429.901

30. Kastenmayer JP, Ni L, Chu A, Kitchen LE, Au WC, Yang H, Carter CD, Wheeler D, Davis RW, Boeke JD, Snyder MA, Basrai MA (2006). Functional genomics of genes with small open reading frames (sORFs) in $S$. cerevisiae. Genome Res 16(3): 365-373. doi: 10.1101/gr.4355406

31. Grünenfelder B, Winzeler EA (2002). Treasures and traps in genome-wide data sets: case examples from yeast. Nat Rev Genet 3(9): 653-661. doi: 10.1038/nrg886

32. Scherens B, Goffeau A (2004). The uses of genome-wide yeast mutant collections. Genome Biol 5(7): 229. doi: 10.1186/gb-2004-5-7229

33. Hughes TR, Roberts CJ, Dai H, Jones AR, Meyer MR, Slade D, Burchard J, Dow S, Ward TR, Kidd MJ, Friend SH, Marton MJ (2000). Widespread aneuploidy revealed by DNA microarray expression profiling. Nat Genet 25(3): 333-337. doi: 10.1038/77116

34. Teng X, Dayhoff-Brannigan M, Cheng WC, Gilbert CE, Sing CN, Diny NL, Wheelan SJ, Dunham MJ, Boeke JD, Pineda FJ, Hardwick JM (2013). Genome-wide consequences of deleting any single gene. Mol Cell 52(4): 485-494. doi: 10.1016/j.molcel.2013.09.026

35. Ben-Shitrit T, Yosef N, Shemesh K, Sharan R, Ruppin E, Kupiec M (2012). Systematic identification of gene annotation errors in the widely used yeast mutation collections. Nat Methods 9(4): 373-378. doi: $10.1038 /$ nmeth.1890

36. Cherry JM, Hong EL, Amundsen C, Balakrishnan R, Binkley G, Chan ET, Christie KR, Costanzo MC, Dwight SS, Engel SR, Fisk DG, Hirschman JE, Hitz BC, Karra K, Krieger CJ, Miyasato SR, Nash RS, Park J, Skrzypek MS, Simison M, Weng S, Wong ED (2012). Saccharomyces Genome Database: the genomics resource of budding yeast. Nucleic Acids Res 40: D700-705. doi: 10.1093/nar/gkr1029

37. Ohya $Y$, Umemoto N, Tanida I, Ohta A, lida H, Anraku Y (1991). Calcium-sensitive cls mutants of Saccharomyces cerevisiae showing a Pet phenotype are ascribable to defects of vacuolar membrane $\mathrm{H}^{+}$ATPase activity. J Biol Chem 266(21): 13971-13977. PMID: 1830311

38. Eide DJ, Bridgham JT, Zhao Z, Mattoon JR (1993). The vacuolar $\mathrm{H}(+)$-ATPase of Saccharomyces cerevisiae is required for efficient copper detoxification, mitochondrial function, and iron metabolism. Mol Gen Genet 241(3-4): 447-456. doi: 10.1007/bf00284699

39. Schlecht U, Suresh S, Xu W, Aparicio AM, Chu A, Proctor MJ, Davis RW, Scharfe C, St Onge RP (2014). A functional screen for copper homeostasis genes identifies a pharmacologically tractable cellular system. BMC Genomics 15: 263. doi: 10.1186/1471-2164-15-263

40. Diab HI, Kane PM (2013). Loss of vacuolar $\mathrm{H}^{+}$-ATPase (V-ATPase) activity in yeast generates an iron deprivation signal that is moderated by induction of the peroxiredoxin TSA2. J Biol Chem 288(16): 1136611377. doi: 10.1074/jbc.M112.419259

41. Chen KL, Ven TN, Crane MM, Brunner MLC, Pun AK, Helget KL, Brower K, Chen DE, Doan H, Dillard-Telm JD, Huynh E, Feng YC, Yan Z, Golubeva A, Hsu RA, Knight R, Levin J, Mobasher V, Muir M, Omokehinde V, Screws C, Tunali E, Tran RK, Valdez L, Yang E, Kennedy SR, Herr AJ, Kaeberlein M, Wasko BM (2020). Loss of vacuolar acidity results in iron-sulfur cluster defects and divergent homeostatic responses during aging in Saccharomyces cerevisiae. Geroscience 42(2):749-764. doi: 10.1007/s11357-020-00159-3

42. Hughes CE, Coody TK, Jeong MY, Berg JA, Winge DR, Hughes AL (2020). Cysteine toxicity drives age-related mitochondrial decline by altering iron homeostasis. Cell 180(2): 296-310 e218. doi: 10.1016/j.cell.2019.12.035

43. Brachmann CB, Davies A, Cost GJ, Caputo E, Li J, Hieter P, Boeke JD (1998). Designer deletion strains derived from Saccharomyces cerevisiae S288C: a useful set of strains and plasmids for PCR-mediated gene disruption and other applications. Yeast 14(2): 115-132. doi: 10.1002/(SICI)1097-0061(19980130)14:2<115::AID-YEA204>3.0.CO;22

44. Mortimer RK, Johnston JR (1986). Genealogy of principal strains of the yeast genetic stock center. Genetics 113(1): 35-43. PMID: 3519363

45. Goffeau A, Barrell BG, Bussey H, Davis RW, Dujon B, Feldmann H, Galibert F, Hoheisel JD, Jacq C, Johnston M, Louis EJ, Mewes HW, Murakami Y, Philippsen P, Tettelin H, Oliver SG (1996). Life with 6000 genes. Science 274(5287): 546-552. doi: 10.1126/science.274.5287.546

46. Dimitrov LN, Brem RB, Kruglyak L, Gottschling DE (2009). Polymorphisms in multiple genes contribute to the spontaneous mitochondrial genome instability of Saccharomyces cerevisiae S288C strains. Genetics 183(1): 365-383. doi: 10.1534/genetics.109.104497

47. Lewis JA, Broman AT, Will J, Gasch AP (2014). Genetic architecture of ethanol-responsive transcriptome variation in Saccharomyces cerevisiae strains. Genetics 198(1): 369-382. doi 10.1534/genetics.114.167429

48. Traba J, Froschauer EM, Wiesenberger G, Satrustegui J, Del Arco A (2008). Yeast mitochondria import ATP through the calciumdependent ATP-Mg/Pi carrier Sal1p, and are ATP consumers during aerobic growth in glucose. Mol Microbiol 69(3): 570-585. doi: 10.1111/j.1365-2958.2008.06300.x

49. Jonassen T, Proft M, Randez-Gil F, Schultz JR, Marbois BN, Entian $\mathrm{KD}$, Clarke CF (1998). Yeast Clk-1 homologue (Coq7/Cat5) is a mitochondrial protein in coenzyme Q synthesis. J Biol Chem 273(6): 33513357. doi: $10.1074 /$ jbc. 273.6 .3351

50. Foury $F(1989)$. Cloning and sequencing of the nuclear gene MIP1 encoding the catalytic subunit of the yeast mitochondrial DNA polymerase. J Biol Chem 264(34): 20552-20560. PMID: 2684980

51. Gaisne M, Becam AM, Verdiere J, Herbert CJ (1999). A 'natural' mutation in Saccharomyces cerevisiae strains derived from S288c affects the complex regulatory gene HAP1 (CYP1). Curr Genet 36(4): 195-200. doi: 10.1007/s002940050490

52. Youngman MJ, Aiken Hobbs AE, Burgess SM, Srinivasan M, Jensen RE (2004). Mmm2p, a mitochondrial outer membrane protein required for yeast mitochondrial shape and maintenance of mtDNA nucleoids. J Cell Biol 164(5): 677-688. doi: 10.1083/jcb.200308012

53. Lang $A B$, John Peter AT, Walter $P$, Kornmann B (2015). ERmitochondrial junctions can be bypassed by dominant mutations in the endosomal protein Vps13. J Cell Biol 210(6): 883-890. doi: $10.1083 /$ jcb. 201502105

54. Chan EYL, McQuibban GA (2012). Phosphatidylserine decarboxylase 1 (Psd1) promotes mitochondrial fusion by regulating the biophysical properties of the mitochondrial membrane and alternative topogenesis of mitochondrial genome maintenance protein 1 (Mgm1). J Biol Chem 287(48): 40131-40139. doi: 10.1074/jbc.M112.399428

55. Sherman F (2002). Getting started with yeast. Methods Enzymol 350: 3-41. doi: 10.1016/s0076-6879(02)50954-x

56. Fox TD, Folley LS, Mulero JJ, McMullin TW, Thorsness PE, Hedin LO, Costanzo MC (1991). Analysis and manipulation of yeast mitochondrial genes. Methods Enzymol 194: 149-165. doi: 10.1016/00766879(91)94013-3 
57. Spencer JFT, Spencer DM (1996). Rare-mating and cytoduction in Saccharomyces cerevisiae. Meth Mol Biol 53: 39-44. doi: 10.1385/089603-319-8:39

58. Chen XJ, Clark-Walker GD (2000). The petite mutation in yeasts: 50 years on. Int Rev Cytol 194: 197-238. doi: 10.1016/S00747696(08)62397-9

59. Dunn CD, Lee MS, Spencer FA, Jensen RE (2006). A genomewide screen for petite-negative yeast strains yields a new subunit of the $i-$ AAA protease complex. Mol Biol Cell 17(1): 213-226. doi: 10.1091/mbc.e05-06-0585

60. Lettier G, Feng $Q$, de Mayolo AA, Erdeniz N, Reid RJ, Lisby M, Mortensen UH, Rothstein R (2006). The role of DNA double-strand breaks in spontaneous homologous recombination in $S$. cerevisiae. PLoS Genet 2(11): e194. doi: 10.1371/journal.pgen.0020194

61. Sayas E, Garcia-Lopez F, Serrano R (2015). Toxicity, mutagenicity and transport in Saccharomyces cerevisiae of three popular DNA intercalating fluorescent dyes. Yeast 32(9): 595-606. doi: 10.1002/yea.3081

62. Sickmann A, Reinders J, Wagner Y, Joppich C, Zahedi R, Meyer HE, Schönfisch B, Perschil I, Chacinska A, Guiard B, Rehling P, Pfanner N, Meisinger $C$ (2003). The proteome of Saccharomyces cerevisiae mitochondria. Proc Natl Acad Sci USA 100(23): 13207-13212. doi: 10.1073/pnas. 2135385100

63. Ott M, Amunts A, Brown A (2016). Organization and regulation of mitochondrial protein synthesis. Annu Rev Biochem 85: 77-101. doi: 10.1146/annurev-biochem-060815-014334

64. Heimberg H, Boyen A, Crabeel M, Glansdorff N (1990). Escherichia coli and Saccharomyces cerevisiae acetylornithine aminotransferase: evolutionary relationship with ornithine aminotransferase. Gene 90(1): 69-78. doi: 10.1016/0378-1119(90)90440-3

65. Jauniaux JC, Urrestarazu LA, Wiame JM (1978). Arginine metabolism in Saccharomyces cerevisiae: subcellular localization of the enzymes. J Bacteriol 133(3): 1096-1107. doi: 10.1128/jb.133.3.10961107.1978

66. Steele DF, Butler CA, Fox TD (1996). Expression of a recoded nuclear gene inserted into yeast mitochondrial DNA is limited by mRNAspecific translational activation. Proc Natl Acad Sci USA 93(11): 52535257. doi: 10.1073/pnas.93.11.5253

67. Tong $A H$, Evangelista $M$, Parsons $A B, X u H$, Bader GD, Page $N$, Robinson M, Raghibizadeh S, Hogue CW, Bussey $H$, Andrews B, Tyers $M$, Boone $C$ (2001). Systematic genetic analysis with ordered arrays of yeast deletion mutants. Science 294(5550): 2364-2368. doi: 10.1126/science. 1065810

68. Baryshnikova A, Costanzo M, Dixon S, Vizeacoumar FJ, Myers CL, Andrews B, Boone C (2010). Synthetic genetic array (SGA) analysis in Saccharomyces cerevisiae and Schizosaccharomyces pombe. Methods Enzymol 470: 145-179. doi: 10.1016/S0076-6879(10)70007-0

69. Duvezin-Caubet S, Rak M, Lefebvre-Legendre L, Tetaud E, Bonnefoy N, di Rago JP (2006). A "petite obligate" mutant of Saccharomyces cerevisiae: functional mtDNA is lethal in cells lacking the delta subunit of mitochondrial F1-ATPase. J Biol Chem 281(24): 1630516313. doi: $10.1074 / j b c . M 513805200$

70. Westermann B (2014). Mitochondrial inheritance in yeast. Biochim Biophys Acta 1837(7): 1039-1046. doi: 10.1016/j.bbabio.2013.10.005

71. Zhang H, Singh KK (2014). Global genetic determinants of mitochondrial DNA copy number. PLoS One 9(8): e105242. doi: 10.1371/journal.pone.0105242

72. Göke A, Schrott S, Mizrak A, Belyy V, Osman C, Walter P (2020). Mrx6 regulates mitochondrial DNA copy number in Saccharomyces cerevisiae by engaging the evolutionarily conserved Lon protease Pim1. Mol Biol Cell 31(7): 527-545. doi: 10.1091/mbc.E19-08-0470

73. Puddu F, Herzog M, Selivanova A, Wang S, Zhu J, Klein-Lavi S, Gordon M, Meirman R, Millan-Zambrano G, Ayestaran I, Salguero I, Sharan R, Li R, Kupiec M, Jackson SP (2019). Genome architecture and stability in the Saccharomyces cerevisiae knockout collection. Nature 573(7774): 416-420. doi: 10.1038/s41586-019-1549-9

74. Chen XJ, Clark-Walker GD (2018). Unveiling the mystery of mitochondrial DNA replication in yeasts. Mitochondrion 38: 17-22. doi: 10.1016/j.mito.2017.07.009

75. Myers AM, Pape LK, Tzagoloff A (1985). Mitochondrial protein synthesis is required for maintenance of intact mitochondrial genomes in Saccharomyces cerevisiae. EMBO J 4(8): 2087-2092. doi: 10.1002/j.1460-2075.1985.tb03896.x

76. Chiron S, Suleau A, Bonnefoy N (2005). Mitochondrial translation: elongation factor $\mathrm{Tu}$ is essential in fission yeast and depends on an exchange factor conserved in humans but not in budding yeast. Genetics 169(4): 1891-1901. doi: 10.1534/genetics.104.037473

77. Lipinski KA, Kaniak-Golik A, Golik P (2010). Maintenance and expression of the $S$. cerevisiae mitochondrial genome--from genetics to evolution and systems biology. Biochim Biophys Acta 1797(6-7): 1086-1098. doi: 10.1016/j.bbabio.2009.12.019

78. Kehrein K, Schilling R, Möller-Hergt BV, Wurm CA, Jakobs S, Lamkemeyer T, Langer T, Ott M (2015). Organization of mitochondrial gene expression in two distinct ribosome-containing assemblies. Cell Rep 10(6): 843-853. doi: 10.1016/j.celrep.2015.01.012

79. Gietz D, Jean AS, Woods RA, Schiestl RH (1992). Improved method for high efficiency transformation of intact yeast cells. Nucl Acids Res 20(6): 1425. doi: 10.1093/nar/20.6.1425

80. Böckler S, Chelius X, Hock N, Klecker T, Wolter M, Weiss M, Braun RJ, Westermann B (2017). Fusion, fission, and transport control asymmetric inheritance of mitochondria and protein aggregates. J Cell Biol 216(8): 2481-2498. doi: 10.1083/jcb.201611197

81. Longtine MS, McKenzie A, 3rd, Demarini DJ, Shah NG, Wach A, Brachat A, Philippsen P, Pringle JR (1998). Additional modules for versatile and economical PCR-based gene deletion and modification in Saccharomyces cerevisiae. Yeast 14(10): 953-961. doi 10.1002/(SICI)1097-0061(199807)14:10<953::AID-YEA293>3.0.CO;2-U

82. Boeke JD, LaCroute F, Fink GR (1984). A positive selection for mutants lacking orotidine-5-phosphate decarboxylase activity in yeast: 5fluoro-orotic acid resistance. Mol Gen Genet 197(2): 345-346. doi: 10.1007/BF00330984

83. Ahmad M, Bussey $H$ (1986). Yeast arginine permease: nucleotide sequence of the CAN1 gene. Curr Genet 10(8): 587-592. doi: 10.1007/BF00418125

84. Sikorski RS, Hieter P (1989). A system of shuttle vectors and host strains designed for efficient manipulation of DNA in Saccharomyces cerevisiae. Genetics 122(1): 19-27. PMID: 2659436

85. Janke C, Magiera MM, Rathfelder N, Taxis C, Reber S, Maekawa $H$, Moreno-Borchart A, Doenges G, Schwob E, Schiebel E, Knop M (2004). $A$ versatile toolbox for PCR-based tagging of yeast genes: new fluorescent proteins, more markers and promoter substitution cassettes. Yeast 21(11): 947-962. doi: 10.1002/yea.1142

86. Sherman $F$ (1963). Respiration-deficient mutants of yeast. I. Genetics. Genetics 48(3): 375-385. PMID: 13977171

87. Conde J, Fink GR (1976). A mutant of Saccharomyces cerevisiae defective for nuclear fusion. Proc Natl Acad Sci USA 73(10): 36513655. doi: 10.1073/pnas.73.10.3651 